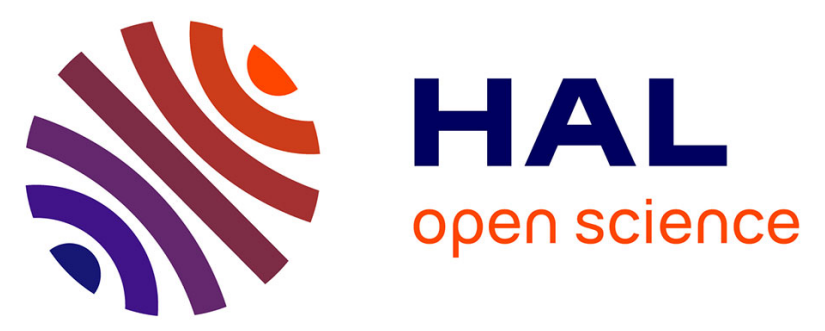

\title{
Novel 2,7-Diazaspiro[4,4]nonane Derivatives to Inhibit Mouse and Human Osteoclast Activities and Prevent Bone Loss in Ovariectomized Mice without Affecting Bone Formation
}

\author{
Lucile Mounier, Anne Morel, Yann Ferrandez, Jukka Morko, Jukka \\ Vääräniemi, Marine Gilardone, Didier Roche, Jacqueline Cherfils, Anne \\ Blangy
}

\section{- To cite this version:}

Lucile Mounier, Anne Morel, Yann Ferrandez, Jukka Morko, Jukka Vääräniemi, et al.. Novel 2,7Diazaspiro[4,4]nonane Derivatives to Inhibit Mouse and Human Osteoclast Activities and Prevent Bone Loss in Ovariectomized Mice without Affecting Bone Formation. Journal of Medicinal Chemistry, 2020, 10.1021/acs.jmedchem.0c01201 . hal-03006787

\section{HAL Id: hal-03006787 https://hal.science/hal-03006787}

Submitted on 16 Nov 2020

HAL is a multi-disciplinary open access archive for the deposit and dissemination of scientific research documents, whether they are published or not. The documents may come from teaching and research institutions in France or abroad, or from public or private research centers.
L'archive ouverte pluridisciplinaire HAL, est destinée au dépôt et à la diffusion de documents scientifiques de niveau recherche, publiés ou non, émanant des établissements d'enseignement et de recherche français ou étrangers, des laboratoires publics ou privés. 
Novel 2,7-Diazaspiro[4,4]nonane derivatives to inhibit mouse and human osteoclast activities and to prevent bone loss in ovariectomized mice without affecting bone formation.

Lucile Mounier $^{\dagger}$, Anne Morel ${ }^{\dagger}$, Yann Ferrandez ${ }^{\ddagger}$ Jukka Morko", Jukka Vääräniemi" , Marine Gilardone $^{\perp}$, Didier Roche ${ }^{\perp}$, Jacqueline Cherfils ${ }^{\ddagger}$, Anne Blangy ${ }^{\dagger}$,*

${ }^{\dagger}$ Centre de Recherche de Biologie Cellulaire de Montpellier, CRBM, Univ Montpellier, CNRS, 34000 Montpellier, France.

‡ Laboratoire de Biologie et Pharmacologie Appliquée, CNRS, Ecole Normale Supérieure Paris-Saclay and Université Paris-Saclay, 91190 Gif-sur-Yvette, France

" Pharmatest Services Ltd., Itäinen Pitkäkatu 4, 20520 Turku, Finland

${ }^{\perp}$ Edelris, 60 avenue Rockefeller, 69008 Lyon, France.

${ }^{*}$ Corresponding author:

BLANGY Anne, anne.blangy@crbm.cnrs.fr

Postal address: CNRS UMR 5237 CRBM

1919 Route de Mende - 34293 Montpellier Cedex 5- FRANCE

Tel : +33434359508 - Fax : +33434359410 


\section{ABSTRACT}

Osteoporosis is currently treated with drugs targeting the differentiation or viability osteoclasts, the cells responsible for physiological and pathological bone resorption. Nevertheless, osteoporosis drugs that would target only osteoclast activity are expected to preserve bone formation by osteoblasts, in contrast with current treatments. We report here the design, synthesis and biological characterization of a series of novel $\mathrm{N}$-arylsufonamides featuring a diazaspiro[4,4]nonane nucleus to target the guanine nucleotide exchange activity of DOCK5, which is essential for bone resorption by osteoclasts. These compounds can inhibit both mouse and human osteoclast activity. In particular, 4-chlorobenzyl-4-hydroxy-2phenyl-1-thia-2,7-diazaspiro[4,4]nonane 1,1-dioxide (compound E197) prevented pathological bone loss in the mouse. Most interestingly, treatment E197 did not affect osteoclast and osteoblast numbers and hence did not impair bone formation. E197 could represent a lead molecule to develop new anti-osteoporotic drugs targeting the mechanism of osteoclast adhesion onto the bone.

\section{KEY WORDS}

Osteoporosis, Preclinical Studies, Osteoclast, diazaspiro[4,4]nonane, Bone histomorphometry 


\section{INTRODUCTION}

Bone is a dynamic tissue undergoing permanent remodeling throughout life: it is continually resorbed by osteoclasts, which are myeloid cells, and replaced by osteoblasts, which are mesenchymal cells ${ }^{1,2}$. Bone modeling and remodeling are necessary for fracture healing and adaptation of the skeleton to load and to mechanical use, as well as for calcium and phosphorus homeostasis. An imbalance between bone resorption and bone formation results in several bone diseases. In particular, excessive resorption activity of osteoclasts, resulting in bone loss and eventually osteoporosis, occurs in a number of physiopathological conditions. Osteoclast hyperactivity indeed accompanies hormone deficiency after menopause ${ }^{3}$, rheumatoid arthritis and other inflammatory diseases ${ }^{4,5}$, multiple myeloma and numerous cancers that metastasize to the bone ${ }^{6}$, corticotherapy ${ }^{7}$, and also the lack of mechanical forces applied to the bone, as for instance upon prolonged bed rest or spinal cord injury ${ }^{8}$. Several infectious diseases are also characterized by abnormal bone $\operatorname{loss}^{9}$. Currently, the most widely used clinical treatments to prevent osteoporosis target osteoclast differentiation and survival. The bisphosphonates are pyrophosphate analogs that bind to the bone, they are ingested by the bone-resorbing osteoclasts and cause their apoptosis ${ }^{10}$, whereas monoclonal antibody denosumab targets receptor activator of nuclear factor- $\kappa \mathrm{B}$ ligand (RANKL), the cytokine essential for osteoclast differentiation ${ }^{11}$. But these treatments hamper the stimulatory activity of osteoclasts on osteoblast differentiation and on bone formation activity; as a consequence, patients receiving these drugs suffer from a blockade of de novo bone formation ${ }^{12,13}$. In fact, osteoclasts were found able to stimulate bone formation, independent of bone resorption ${ }^{14}$. Whereas the mechanisms are not completely understood, several proteins secreted by nonresorbing osteoclasts and collectively called clastokines were found to stimulate osteoblast differentiation $^{12}$, such as Wnt10b or the chemokine sphingosine-1-phosphate $\mathrm{S} \mathrm{P}^{15}$. Thus, targeting specifically osteoclast bone-resorption function, instead of osteoclast differentiation 
and viability, appears an attractive strategy to control bone resorption without affecting bone formation $^{14}$. Indeed, Odanacatib, an inhibitor of the key osteoclast protease Cathespin K, proved efficient at preventing pathological bone loss while preserving bone formation in patients but unfortunately, the molecule recently failed in clinical phase III trials due to increased risk of stroke ${ }^{16}$.

Targeting osteoclast adhesion structures on bone also appears as a tempting strategy ${ }^{17}$, still in the preclinical or early clinical stage. The resorbing osteoclasts is attached on the bone through a unique adhesion structure based on a belt of podosomes; the podosomes attach osteoclasts on the bone matrix via $\alpha \mathrm{v} \beta 3$, the major osteoclast integrin and perturbing the organization of podosomes in osteoclasts prevents bone resorption ${ }^{17}$. Indeed, an inhibitor of $\alpha v \beta 3$ allowed reducing osteoclast activity and proved efficient to protect women from postmenopausal bone loss in a phase I study ${ }^{18}$. Another approach is to aim at the regulators of the dynamics of actin, the major component of podosomes. We reported previously the identification of a small chemical compound inhibiting the activity of DOCK5, a guanine nucleotide exchange factor (GEF) of the small GTPase Rac essential to assemble the podosome belt in mouse osteoclasts ${ }^{19,20}$. The commercial molecule N-(3,5-Dichlorophenyl) benzenesulfonamide (C21, CAS 54129-15-6) disorganizes the podosome belt and hinders osteoclast activity $^{20}$. When administered to the mouse, $\mathbf{C 2 1}$ prevented pathological bone loss, while bone formation by osteoblasts was maintained, making this a promising strategy to prevent pathological bone $\operatorname{loss}^{21}$. In this study, based on the structure of $\mathbf{C 2 1}$, we identified a identified a new $N$-arylsufonamides family of compounds featuring a $[4,4]$ nonane nucleus that inhibit DOCK5 exchange activity. We showed that these compounds not only disorganized reversibly mouse osteoclast podosomes and prevented their activity, as C21 does $^{20,21}$, but also hindered the activity of human osteoclasts, contrarily to $\mathbf{C 2 1}$. Moreover, we tested one of the $\mathrm{N}$-arylsufonamide compounds in vivo in the mouse model of ovariectomy 
(OVX)-induced bone loss and we found that could prevent pathological bone, while bone formation was preserved. 


\section{RESULTS AND DISCUSSION}

Identification of an inhibitor of human DOCK5 exchange activity. The inhibition of DOCK5 exchange activity towards the GTPase Rac with N-(3,5-Dichlorophenyl) benzenesulfonamide (C21, Figure 1A), prevents bone resorption by mouse osteoclasts by disorganizing their cytoskeleton and it efficiently protected mice against pathological bone loss in various mouse models of pathological bone loss without affecting bone formation ${ }^{20,21}$. This established that DOCK5 inhibition could represent an interesting therapeutic strategy against osteoporosis. Nevertheless, we found that C21 did not inhibit the activity of human peripheral blood cell-derived osteoclasts when used up to $30 \mu \mathrm{M}$ (Supplementary Figure 1A). C21 was toxic for human osteoclasts above this dose (Supplementary Figure 1B), consistent with what we had observed previously on mouse osteoclasts ${ }^{20}$. Thus, C21 was not appropriate for further development toward clinical applications.

A<smiles>O=S(=O)(Nc1ccccc1)c1cc(Cl)cc(Cl)c1</smiles>

C21

C<smiles>[R]N1CC[C@]2(C1)[C@@H](O)CN(c1ccccc1)S2(=O)=O</smiles><smiles>CCc1cccc(C)c1</smiles>

E73<smiles>CCc1cnc2ccccc2c1</smiles>

E203<smiles>CCc1ccccc1Cl</smiles>

E196<smiles>CCc1cn(C)c2ccccc12</smiles>

E204
B

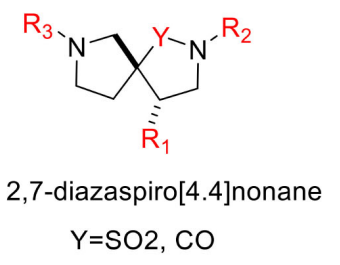

D<smiles>[R9]N1CCC2(CCN(Cc3cccc(Cl)c3)C2)C1=O</smiles><smiles>COc1ccc(C)cc1C</smiles><smiles>Cc1cccc(F)c1</smiles><smiles>CCc1ccc(Cl)cc1</smiles>

E197<smiles>CCOCCc1ccc2c(c1)CCC2</smiles><smiles>CCc1ccc(OC)c(F)c1</smiles> 
Figure 1: Chemical structures of the compounds. (A) C21: N-(3,5-Dichlorophenyl) benzenesulfonamide and E73: rac-(4S,5R)-7-(3-chlorobenzyl)-4-hydroxy-2-phenyl-1-thia-2,7-diazaspiro[4,4]nonane 1,1-dioxide. (B) General structure of $\mathbf{E 7 3}$ and its derivatives. (C-D) Structures of E73 analogs. E196: rac-(4S,5R)-7-(2chlorobenzyl)-4-hydroxy-2-phenyl-1-thia-2,7-diazaspiro[4,4]nonane 1,1-dioxide, $\quad$ E197: rac-(4S,5R)-7-(4chlorobenzyl)-4-hydroxy-2-phenyl-1-thia-2,7-diazaspiro[4,4]nonane 1,1-dioxide, $\quad$ E202: rac-(4S,5R)-7-(3,4dichlorobenzyl)-4-hydroxy-2-phenyl-1-thia-2,7-diazaspiro[4,4]nonane $\quad$ 1,1-dioxide, $\quad$ E203: $\quad$ rac-(4S,5R)-4hydroxy-2-phenyl-7-(quinolin-3-ylmethyl)-1-thia-2,7-diazaspiro[4,4]nonane 1,1-dioxide, E204: rac-(4S,5R)-4hydroxy-7-((1-methyl-1H-indol-3-yl) methyl)-2phenyl-1-thia-2,7-diazaspiro[4,4]nonane 1,1-dioxide. E210: rac(4S,5R)-7-((2,3-dihydro-1H-inden-5-yl)methyl)-4-hydroxy-2-phenyl-1-thia-2,7-diazaspiro[4,4]nonane 1,1dioxide E211: rac-(4S,5R)-7-(3-fluoro4-methoxybenzyl)-4-hydroxy-2-phenyl-1-thia-2,7-diazaspiro[4,4]nonane 1,1-dioxide, E226: 7-(3-chlorobenzyl)-2-(3-fluorophenyl)-2,7-diazaspiro[4,4]nonane-1-one and E228: 7-(3chlorobenzyl)-2-(4-metoxy-3-methylphenyl)-2,7-diazaspiro[4,4]nonane-1-one.

We therefore decided to screen a larger set of compounds while keeping a certain level of homology with C21. For this purpose, a library of 100 compounds featuring the arylsulfonamide substructure of $\mathbf{C 2 1}$ was selected from a commercial provider and screen on the inhibitory activity on mouse DOCK5. For this, we expressed the exchange domain of mouse DOCK5 in HEK293T cells to activate endogenous Rac. Then, we treated the cells with the different compounds and monitored Rac activity by pull-down assay (Figure 2A). The levels of active GTP-bound Rac served as read out of the inhibitory effect of the compounds on DOCK5 exchange activity, as we reported earlier for $\mathbf{C 2 1}^{20}$. We measured the level of GTPRac after a 1-hour treatment with each compound at a concentration of $100 \mu \mathrm{M}$ in the culture medium and we compared it to the activity of Rac in control dimethyl sulphoxide (DMSO)treated cells. Very interestingly, compound E73 based on an original diazaspiro[4,4]nonane structure (Figure 1A) was able to inhibit the activation of Rac by mouse DOCK5 (Figure 2B). The potency of E73 appeared higher than that of compound C21 (Figure 2C). Indeed, doseresponse pull-down assays estimated the IC50 of the inhibition of Rac activation by DOCK5 
in HEK293T cells around $43 \mu \mathrm{M}$ for $\mathbf{C 2 1}$ and around $17 \mu \mathrm{M}$ for $\mathbf{E 7 3}$ (Figure 2D-E). Thus,

E73 is a cell-active compound able to inhibit the activation of Rac by DOCK5.
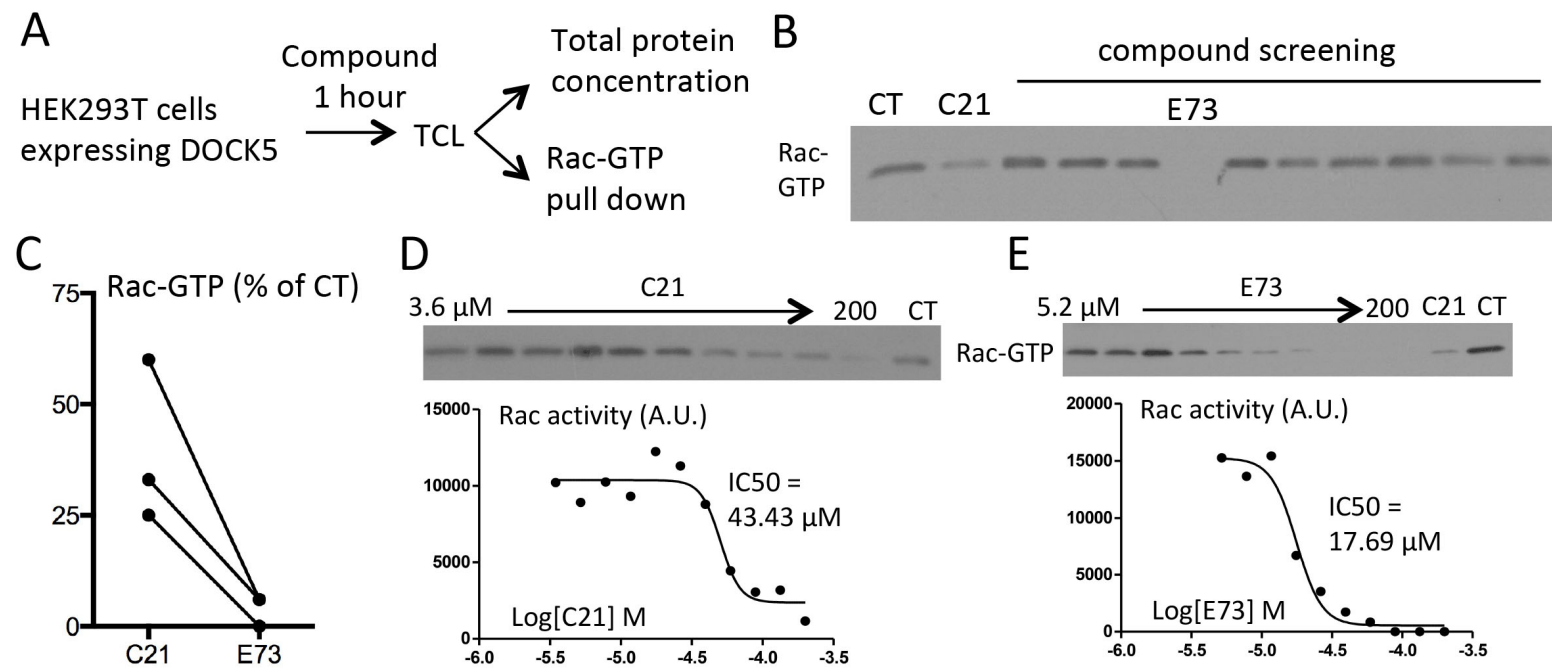

$\mathrm{F}$
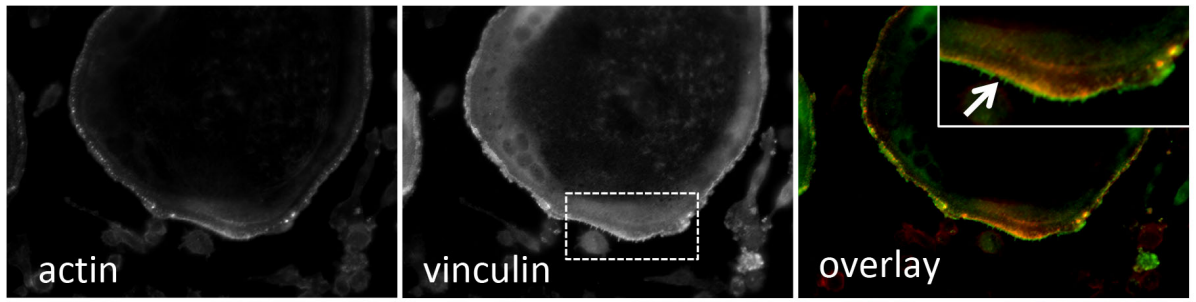

E73
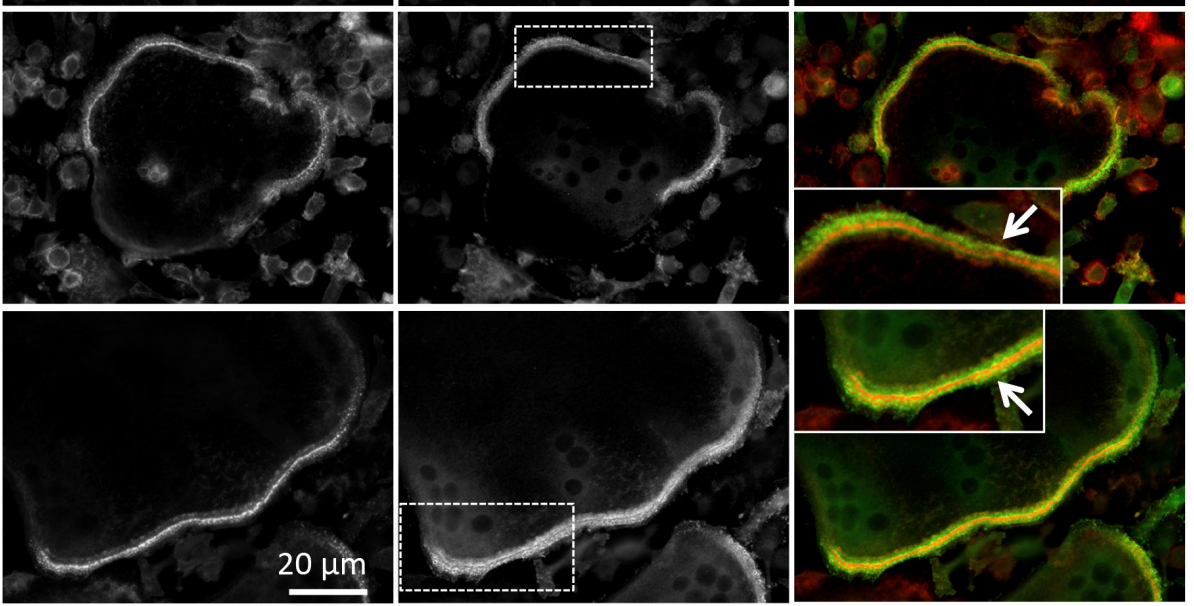

4 hours
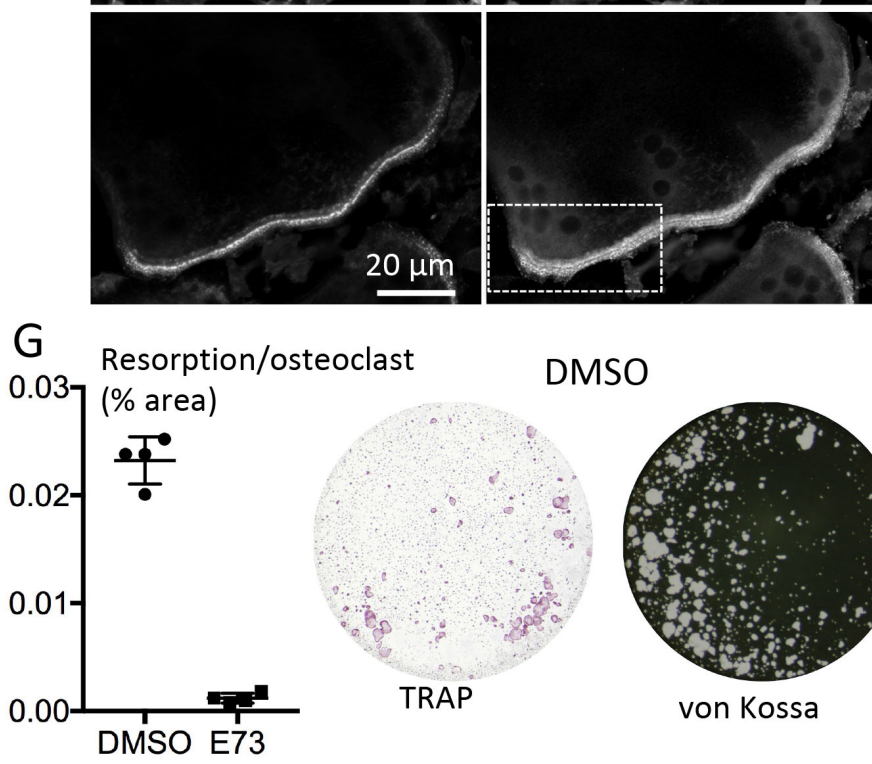

DMSO

$\mathrm{E} 73,8 \mu \mathrm{M}$

\section{DMSO}

\section{$\mathrm{E} 73+$} recovery
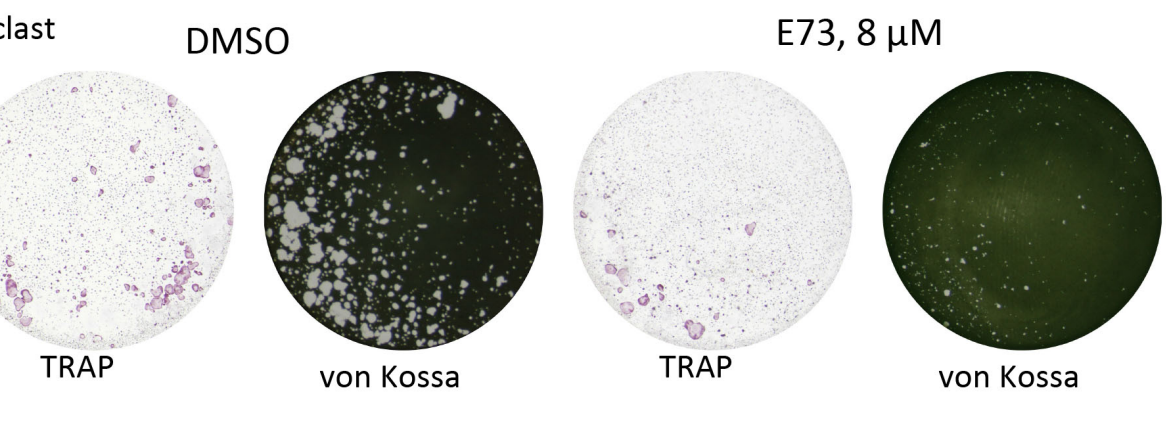
Figure 2: Properties of E73 compound at inhibiting DOCK5 exchange activity and osteoclast function. (A) Principle of compound screening in HEK293T cells by Rac-GTP pull-down assays. DOCK5 is expressed in HEK293T cells to activate endogenous Rac. Cells are incubated for 1 hour with compound and the active form of the GTPase (Rac-GTP) is pulled down from total cell lysates (TCL). Protein concentration in TCL is measured to normalize Rac-GTP levels. (B) Western blot showing the levels of Rac-GTP in HEK293T cells expressing the DHR2 exchange domain of mouse DOCK5 and treated as in A with $0.1 \%$ DMSO (CT) or with $100 \mu \mathrm{M}$ of $\mathbf{C 2 1}$ or of a series of compounds including E73. (C) Comparative efficiency of $100 \mu \mathrm{M}$ of $\mathbf{C 2 1}$ or of E73 at inhibiting mouse DOCK5 exchange activity, in 3 independent pull-down experiments as in B. (D-E) C21 (D) and E73 (E) dose-response (1.5x steps) pull down experiments as in B, to determine the IC50 inhibition of Rac activity by the compounds. (F) Immunofluorescence images showing actin (red) and vinculin (green), with overlay in the right panels, in representative mouse osteoclasts fixed after a 4-hour treatment with $100 \mu \mathrm{M}$ E73 (E73 4 hours), followed by overnight recovery following (E73+revovery) or with $0.25 \%$ DMSO. Arrows point at the characteristic organization of actin and vinculin at the podosome belt, which is lost in E73-treated osteoclasts and recovered after E73 washout. (G) Graph showing mean and standard deviation (SD) of the specific resorption activity of mouse osteoclasts in the presence of $0.5 \%$ DMSO or of $8 \mu \mathrm{M} \mathbf{E 7 3}$ for 48 hours, with representative images of DMSO and E73 wells stained with TRAP (left, pink) to count osteoclasts or with von Kossa (right, black) to measure resorption.

\section{E73 perturbs mouse osteoclast podosome organization and resorption activity. We} reported before that DOCK5 exchange activity on the GTPase Rac is essential for the correct organization of mouse osteoclast podosomes into a belt and consequently for their resorption activity, both being perturbed in the presence of DOCK5 inhibitor $\mathbf{C 2 1}{ }^{20,21}$. Thus, we tested the effect of E73 on the podosome belt. For this, we incubated mouse osteoclasts with $100 \mu \mathrm{M} \mathbf{E 7 3}$ for 4 hours before fixation and staining for actin and vinculin to visualize the podosoem belt (Figure 2F). As compared to DMSO control cells, all osteoclasts treated with E73 exhibited defects in podosome belt organization; this effect proved reversible as the podosome belt was recovered upon washing E73 away (Figure 2F). These results were consistent with what we had observed formerly with DOCK5 inhibitor $\mathbf{C 2 1}{ }^{21}$. This suggests 
that E73 can disorganize mouse osteoclast podosome organization by inhibiting endogenous DOCK5.

We then examined the consequences of E73 treatment on mouse osteoclast activity. Osteoclasts were seeded in multi-well devices coated with calcium phosphate as a bonemimicking mineral substrate and left to resorb the substrate for 48 hours in the presence of $8 \mu \mathrm{M}$ E73. Then, either the wells were stained with von Kossa, to reveal the mineral substrate and measure osteoclast resorption activity, or they were stained for the activity of the tartrate resistant acid phosphatase (TRAP), to reveal osteoclasts and normalize the resorption activity to osteoclast numbers (Figure $2 \mathrm{G}$ ). In the presence of $\mathbf{E 7 3}$, we observed a strongly reduction of the specific activity of mouse osteoclasts as compared to control osteoclasts, treated with DMSO alone (Figure 2G). E73 appeared therefore as a qualified hit for further optimization.

Design and synthesis of E73 derivatives. Nine more analogs of compound E73 were synthesized by modifying the residues R1, R2 and R3 around the 2,7-diazaspiro[4,4]nonane nucleus (Figure 1B). The spiro sultams were prepared in 7 steps from the glycine-aldehyde dimethoxy acetals 1 (Scheme 1). The sultam ring was generated by an intramolecular BaylisHillman reaction previously described ${ }^{22}$. This step was followed by a 1,3-dipolar cycloaddition to introduce the spiro pyrrolidine ring. This reaction led to a major diastereomer (compound 5), which could be purified by flash chromatography. After deprotection under catalytic hydrogenation, the pyrrolidine nitrogen was functionalized with various capping groups by reductive amination. To further assess the structure activity relationship, two lactam derivatives 11a and 11b were also prepared starting from the known 7-benzyl-2,7diazaspiro[4.4]nonan-1-one compound $\mathbf{8}$ synthesized according to a known procedure ${ }^{23}$ (Scheme 2). 
Scheme 1: Synthesis of spiro sultams

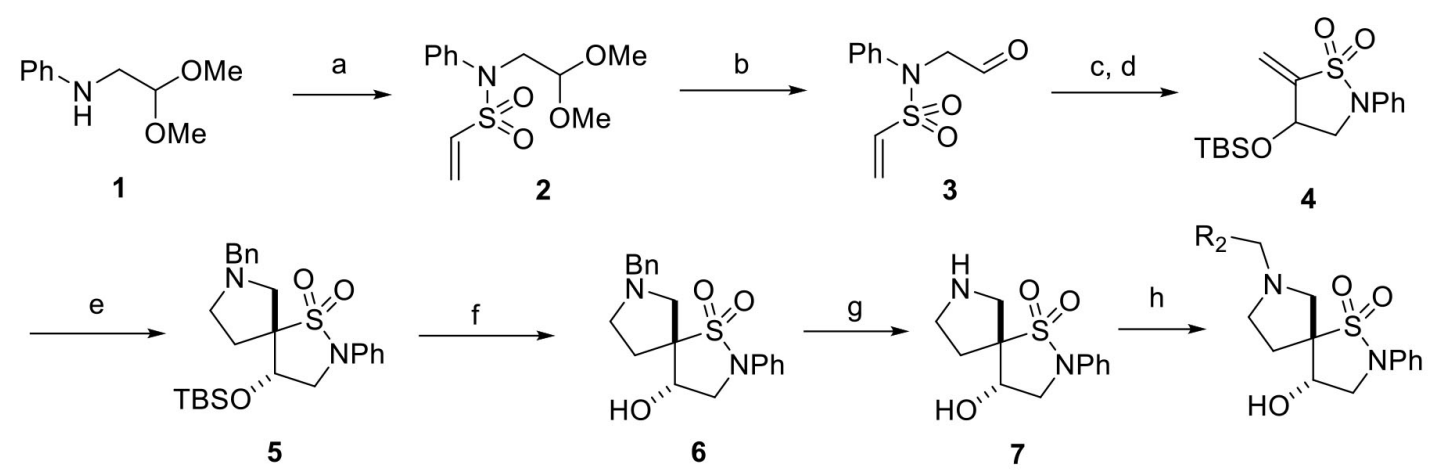

Reagents and conditions: (a) $\mathrm{ClCH}_{2} \mathrm{CH}_{2} \mathrm{SO}_{2} \mathrm{Cl}, \mathrm{Et}_{3} \mathrm{~N}, \mathrm{DCM}$, rt; (b) AcOH-HCl, THF, rt; (c) DABCO, DCM, rt; (d) TBSCl, Imid, rt; (e) $\mathrm{Me}_{3} \mathrm{SiCH}_{2} \mathrm{NBnCH}_{2} \mathrm{OMe}$, TFA, $45^{\circ} \mathrm{C}$; (f) TBAF, THF, rt; (g) $\mathrm{H}_{2}, \mathrm{Pd} / \mathrm{C} 10 \%, \mathrm{AcOH}-\mathrm{EtOH}$, $40^{\circ} \mathrm{C}$; (h) $\mathrm{R}_{2} \mathrm{CHO}, \mathrm{NaBH}(\mathrm{OAc})_{3}$, THF, rt.

\section{Scheme 2: Synthesis of lactam derivatives}

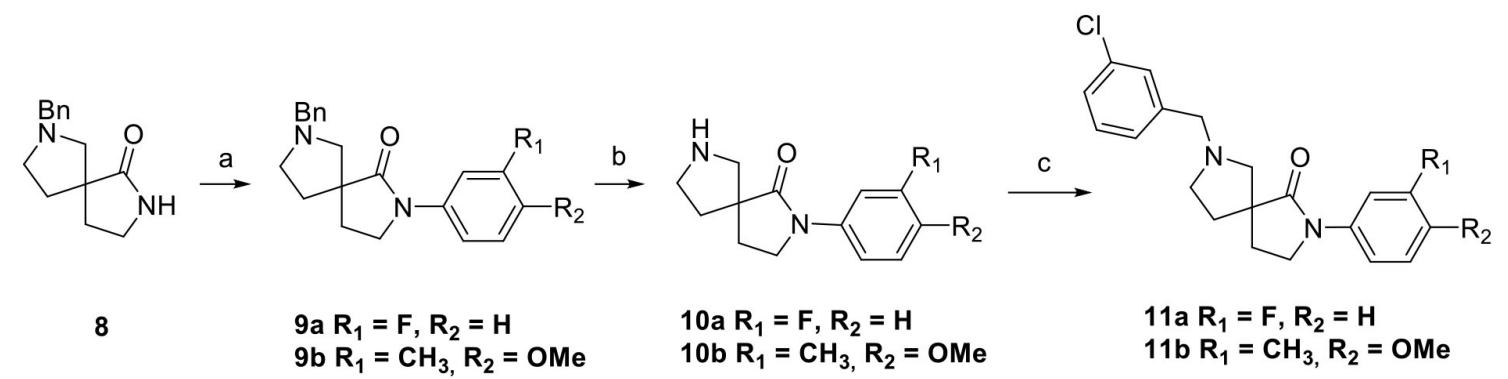

Reagents and conditions: (a) $\mathrm{ArBr}$, Cul, DMEDA, $\mathrm{K}_{3} \mathrm{PO}_{4}$, dioxane, $100^{\circ} \mathrm{C}$; (b) $\mathrm{Pd} / \mathrm{C} 10 \%, \mathrm{AcOH}-\mathrm{EtOH}, 40^{\circ} \mathrm{C}$;

(c) $\mathrm{mClC}_{6} \mathrm{H}_{4} \mathrm{CHO}, \mathrm{NaBH}(\mathrm{OAc})_{3}$, THF, rt.

E73 derivatives active towards human DOCK5 and inhibit mouse osteoclast activity. We then tested E73 and its 9 derivatives in the Rac pull-down reporter assays described in Figure 2A, but this time expressing human DOCK5 to activate endogenous Rac in HEK293T cells, in place of mouse DOCK5 used in Figure 2B-E. Thereby, we determined the IC50 of the inhibition of Rac activation by human DOCK5 (Figure 3A). This showed that E73 also prevented the activation of Rac by human DOCK5 (Figure 3A). Moreover, the 7 close derivatives of E73 were also identified as efficient, non-toxic and soluble hits (E196, E197, E202, E203, E204, E210, E211, Figure 1C) as well as the 2 compounds featuring the spirolactam core (E226 and E228, Figure 1D) (Figure 3A). These results suggest that these 9 novel 
2,7-diazaspiro compounds featuring a $[4,4]$ nonane nucleus are cell active inhibitors of human

\section{DOCK5.}

A

\begin{tabular}{cc} 
Compound & $\mathrm{IC} 50(\mu \mathrm{M})$ \\
\hline E73 & 24 \\
E196 & 35 \\
E197 & 36 \\
E202 & 29 \\
E203 & 22 \\
E204 & 33 \\
E210 & 32 \\
E211 & 44 \\
E226 & 20 \\
E228 & 8
\end{tabular}

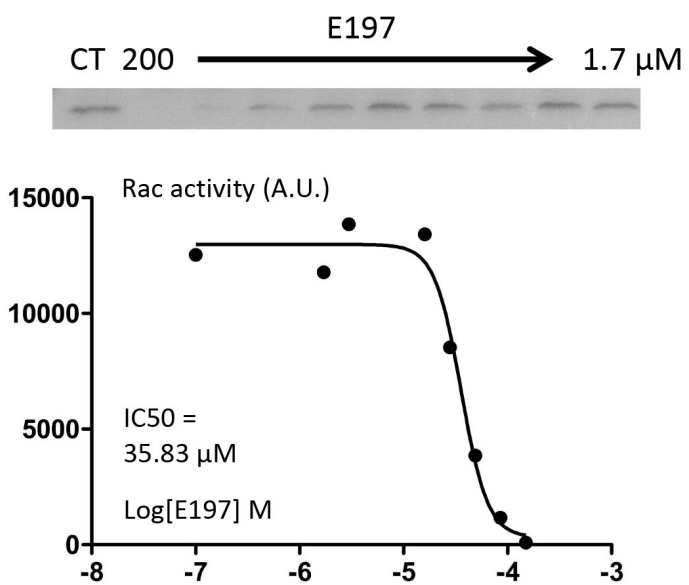

B

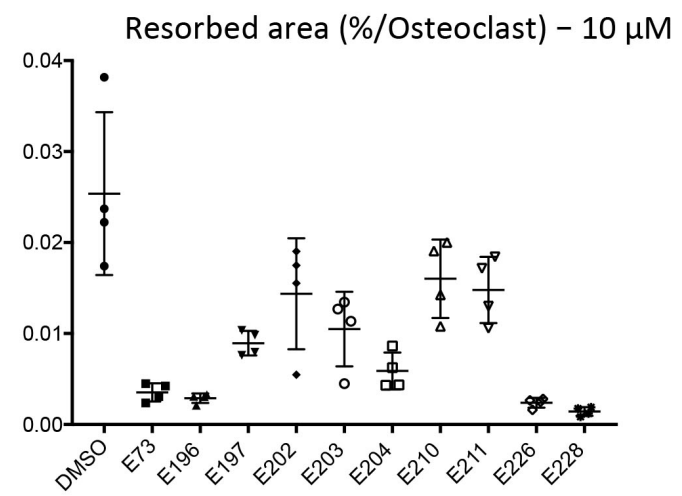

C

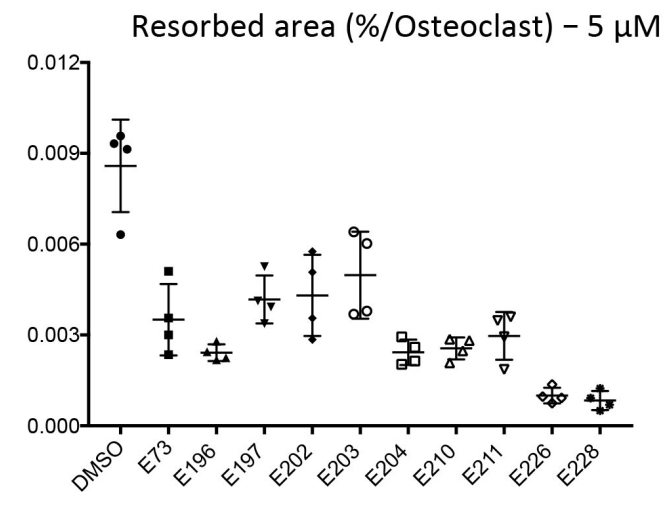

D

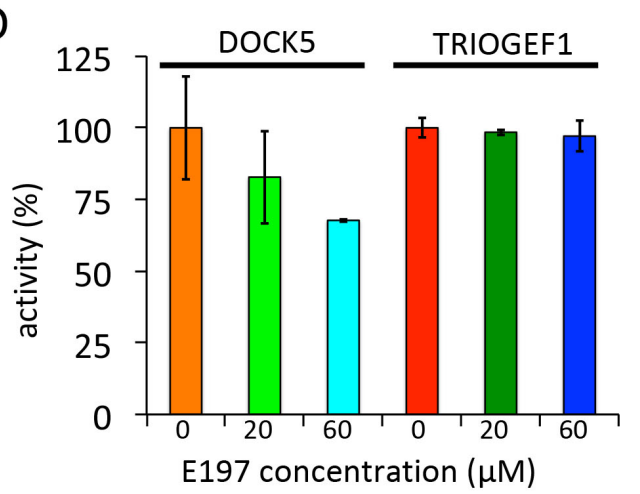

E

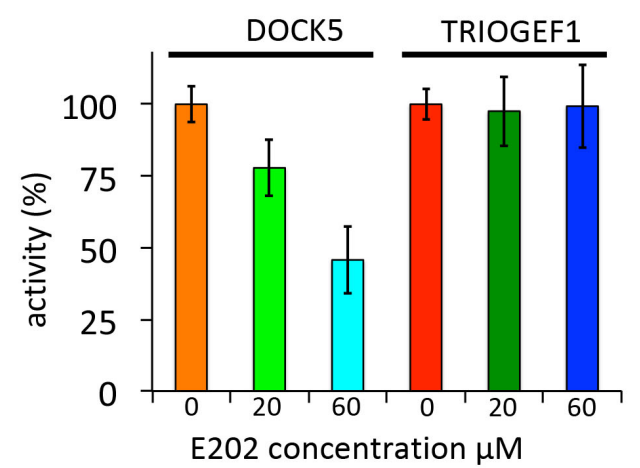

Figure 3. Identification of diazaspiro[4,4]nonane derivatives inhibitors of human DOCK5 and mouse osteoclast activities. (A) Table shows the IC50 inhibition of Rac activity in HEK293T cells expressing human DOCK 5 by E73 and its 9 analogs, determined by Rac pull-down assays as in Figure 2D-E and illustrated for E197. (B-C) Graphs showing the mean with SD of the specific resorption activity of mouse osteoclasts in the presence 0.5\% DMSO (CT) or E73 and its 9 analogs at $10 \mu \mathrm{M}$ (B) or $5 \mu \mathrm{M}$ (C). (D-E) Bar graphs showing the effect of compounds E197 (D) and E202 (E) on DOCK5- and TRIOGEF1-stimulated nucleotide exchange on 
RAC1 in vitro. Experiments were carried out with the purified recombinant proteins shown in Figure S2A. Nucleotide exchange kinetics were monitored by fluorescence and used to determine the $\mathrm{k}_{\mathrm{obs}}\left(\mathrm{s}^{-1}\right)$ in the presence of 0, 20 and $60 \mu \mathrm{M} \mathbf{E 1 9 7}$ (D) and E202 (E). The effect of the compounds is expressed as the percentage of activity with and without the indicated compound, with mean and SD of 2 independent experiments.

We then tested the 9 derivatives of E73 for their effect on mouse osteoclast resorption activity, at concentrations of 5 and $10 \mu \mathrm{M}$. They all inhibited the specificity activity of mouse osteoclast (Figure 3B-C). Nevertheless, the numbers of osteoclasts was strongly reduced after 48 hours in the presence of E226 and E228, (Supplementary Figure 1C), suggesting that the compounds featuring the spiro-lactam core were toxic for osteoclasts.

We then tested the effect of E73 and its 9 analogs in nucleotide exchange assays in vitro. We examined how the compounds affected the kinetics of the Rac nucleotide exchange reaction stimulated by human DOCK5; as a specificity control, we also examined their effect on the activity of TRIO exchange domain 1 (TRIOGEF1), another exchange factor for Rac ${ }^{19,24}$. For this, we purified the GEF domains of the exchange factors and the GTPase RAC1 from E. coli (Supplementary Figure 2A); RAC1 was further loaded with the fluorescent GDP analogue N-methylanthraniloyl-GDP (mant-GDP). The nucleotide exchange efficiency of DOCK5 and TRIOGEF1 towards RAC1 was monitored by the fluorescence decay following mant-GDP dissociation from the GTPase. The kinetics of the exchange reactions $\left(\mathrm{k}_{\mathrm{obs}}\right)$ was measured in the presence of 0,20 or $60 \mu \mathrm{M}$ of each compound. In these nucleotide exchange assays in vitro, E197 and E202 slowed down the exchange reaction stimulated by human DOCK 5 , shown by $45 \%$ and $67 \%$ lower $\mathrm{k}_{\mathrm{obs}}$ respectively, whereas they had no effect on the kinetics of the reaction stimulated by TRIOGEF1 (Figure 3D-E). This indicated that the compounds E197 and E202, which differ by an additional chlorine substitution on the phenyl group in E202, act as direct inhibitors of DOCK5. Nucleotide exchange assays in vitro also showed that C21 was a weaker a weaker inhibitor of human DOCK5 as compared to these 
E197 and E202 (Supplementary Figure 2B), and it also had no measurable effect on human osteoclast resorption activity (Supplementary Figure 1). Different from E197 and E202, the 8 other 2,7-diazaspiro compounds did not inhibit the guanine nucleotide exchange factor activity of DOCK5 in vitro, as exemplified for E73 and E204 (Supplementary figure 2C-D). Accordingly, for further characterization, we retained only compounds E197 and E202, as they were both active in cells (Figures 3 B-C) and directly active towards Dock5 in vitro (Figures 3D-E).

E197 and E202 inhibit human osteoclast activity. We next examined the impact of E197 and E202 on the activity of human peripheral blood cell-derived osteoclasts. For this, human osteoclasts were seeded on calcium phosphate or on plastic and incubated for 48 hours of E197, E202 or the positive control Alendronate, a bisphosphonate used in the clinics. Compound concentrations ranged from 1 to $20 \mu \mathrm{M}$. Human osteoclast were cultured on calcium-phosphate coated wells to measure the effect of the compounds on resorption or on plastic to measure their effect on osteoclast numbers. We did not observe an effect of E197 on osteoclast numbers up to a concentration of $20 \mu \mathrm{M}$, whereas E202 was toxic at $20 \mu \mathrm{M}$ with fewer osteoclasts at the end of the 48-hour experiment (Figure 4A). Both E197 and E202 diminished the specific resorption activity of human osteoclasts, with a specific activity that appeared higher than that of Alendronate (Figure 4B-C). Nevertheless, on top of its toxic effect (Figure 4A), E202 appeared less efficient than E197 (Figure 4C). The estimated IC50 inhibition of human osteoclast activity by E197 was $3.44 \mu \mathrm{M}$ (Figure 4D). Altogether, this shows that the E197 is novel inhibitor of DOCK5 exchange activity that can hinder both mouse and human osteoclast activity, contrarily to the initial compound $\mathbf{C 2 1}$, which was not an efficient inhibitor of human osteoclasts (Supplementary Figure 1A). 

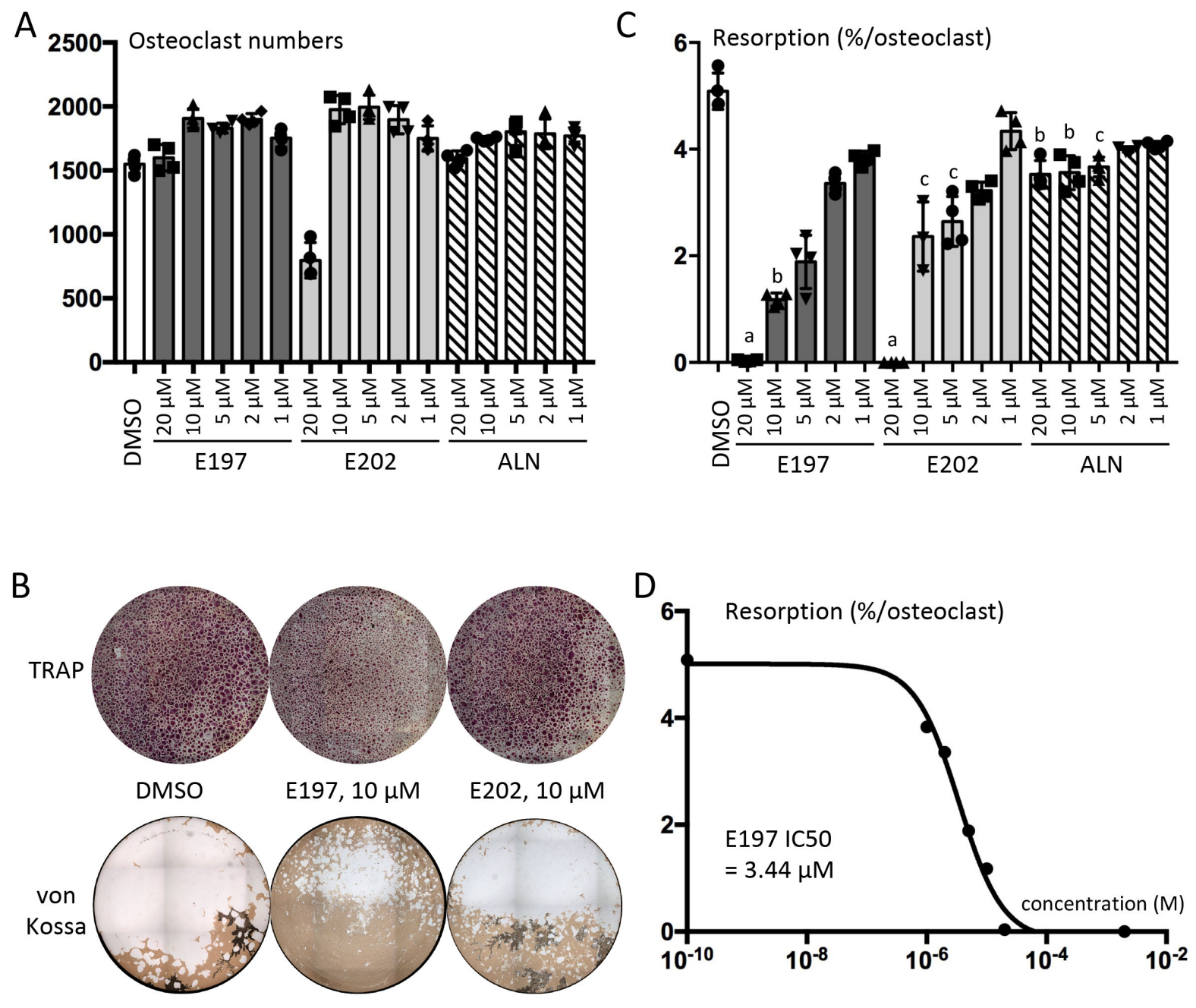

Figure 4. E197 and E202 inhibit human osteoclast activity. (A) Graph showing the mean with SD of human osteoclast numbers after 48-hour culture on calcium phosphate-coated wells in the presence of $0.3 \%$ DMSO or of the indicated concentrations of E179, E202 or the bisphosphonate Alendronate. (B) Representative images of DMSO, $10 \mu \mathrm{M}$ E197 and $10 \mu \mathrm{M}$ E202 wells stained with TRAP (top, pink) to count osteoclasts or with von Kossa (bottom, brown) to measure resorption. (C) Graph showing the mean with SD of the specific resorption activity of human osteoclasts measured after 48-hour culture on calcium phosphate-coated wells in the presence of DMSO or of the indicated concentrations of E197, E202 or Alendronate, as in A. Significant differences relative to the DMSO control: (a) $\mathrm{p}<0.001$; (b) $\mathrm{p}<0.01$; (c) $\mathrm{p}<0.05$, determined by Mann-Whitney test. (D) IC50 of $\mathbf{E} 197$ for the inhibition of human osteoclast activity determined from the data in C.

E197 inhibits ovariectomy-induced bone loss without affecting bone formation. We then moved to the mouse model of ovariectomy (OVX)-induced bone loss to assess the efficacy of 
E197 in vivo. For this, 1 gram of E197 was synthetized and isolated with purity greater than 95\%. Twelve week-old C57BL6/J mice were subjected to OVX or to control SHAM operation. During the 4-week in-life phase of the experiment after surgery, OVX animals received $20 \mathrm{mg} / \mathrm{kg}$ intraperitoneal injections of E197 in 0.5\% carboxymethylcellulose and 3\% Tween 80 once (q.d.) or twice daily (b.i.d.); alternatively, they received either the carboxymethylcellulose/Tween 80 vehicle q.d. or the control bisphosphonate treatment: 100 $\mu \mathrm{g} / \mathrm{kg}$ zoledronate (ZOL) subcutaneously at day 0 and day 14 . SHAM-operated mice receive a q.d. injection of the vehicle. The treatments did not affect mice total body weight (Supplementary figure 3A-B). At day 14, the dosage of bone resorption marker C-terminal cross-linked telopeptides of type I collagen (CTX-I) showed that Zoledronate and E197 b.i.d. prevented OVX-induced elevation of serum CTX-I levels, whereas E197 q.d. had no effect (Table 1). Consistently after 4 weeks, micro-computed tomography ( $\mu \mathrm{CT}$ ) showed that E197 b.i.d.-treated mice had higher bone volume per tissue volume (BV/TV) in tibia metaphysis and diaphysis as compared to OVX animals treated with vehicle (Figure 5A-B). Overall, E197 had little effects on the topological parameters (Table 1). As expected in a mouse overiectomy model $^{25}$, ZOL treatment provoked a very strong increase in the trabecular bone volume at bone metaphysis, above the level of SHAM control mice BV/TV (Figure 5A), and topological parameters were strongly affected (Table 1). This suggests that DOCK5 inhibitor E197 can protect both trabecular and cortical bone against pathological loss. 

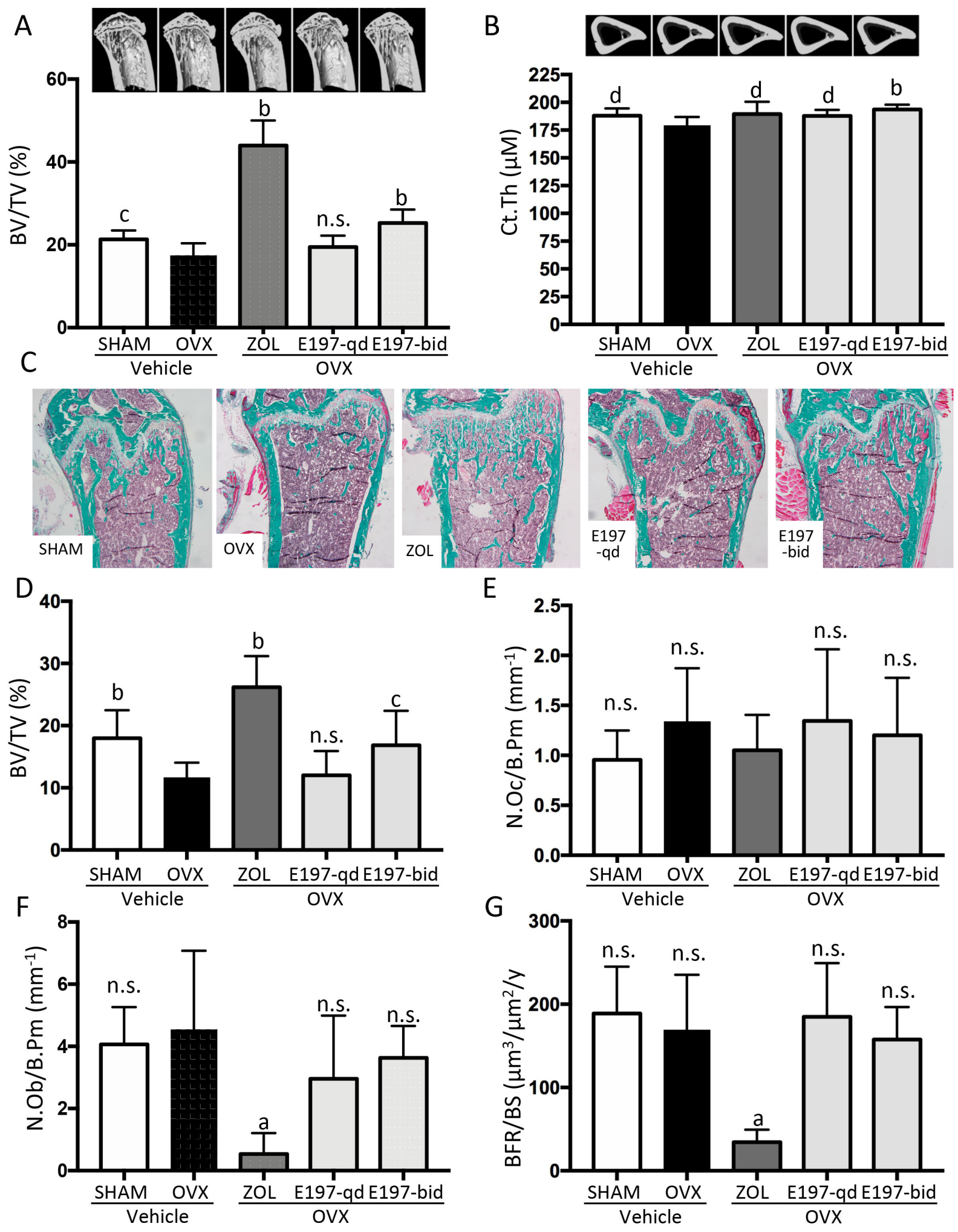

E
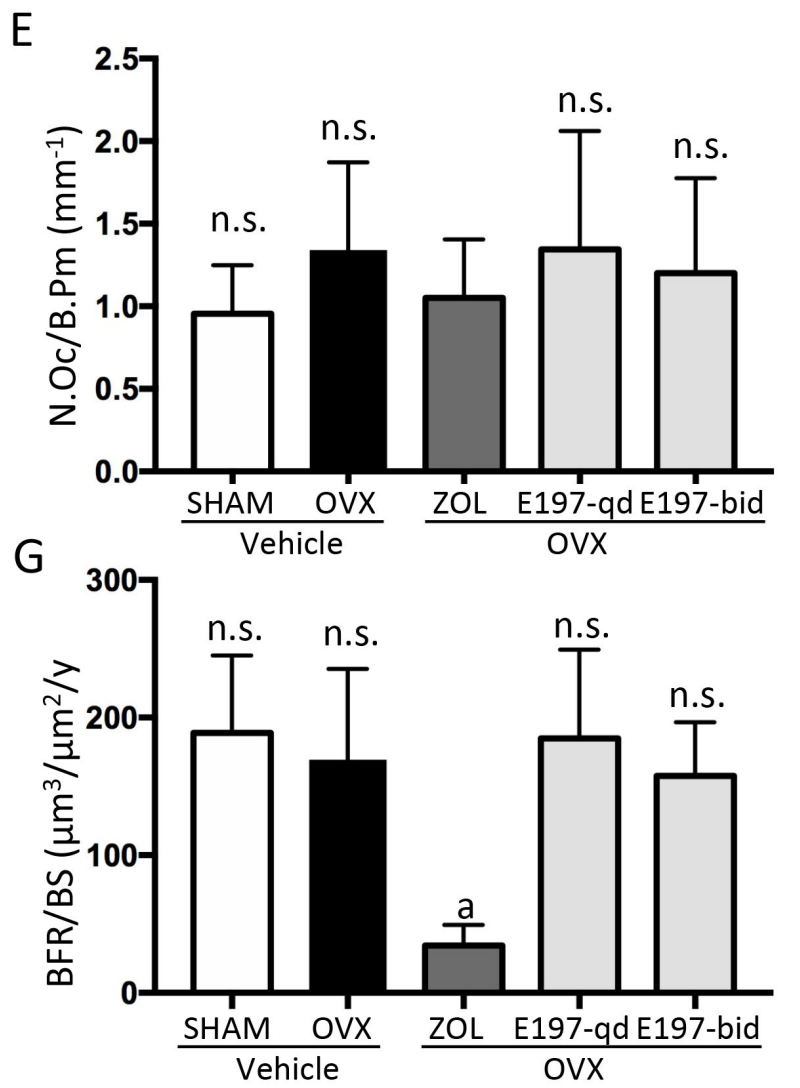

Figure 5. E197 inhibits overiectomy-induced bone loss but has no effect on trabecular bone formation, in contrast with zoledronate. C57B1/6J mice were treated with vehicle or zoledronate (ZOL) or E197, once (qd) or twice (bid) daily, for 4 weeks after ovariectomy (OVX). (A-B) Micro-computed tomography assessment and representative micro-computed tomography images of the right tibia. A: trabecular bone volume over total 
volume $(\mathrm{BV} / \mathrm{TV}, \%)$ and $\mathrm{B}$ : cortical thickness $(\mathrm{Ct} . \mathrm{Th}, \mu \mathrm{M})$ of SHAM-operated (SHAM) mice and OVX mice receiving the different treatments. (C) Representative images of right femur slices stained with MassonGoldner's Trichrome used for bone histomorphometry. (D-G) Bone histomorphometry assessment in distal right femur of: (C) trabecular BV/TV; (D) osteoclast and (E) osteoblast numbers over bone perimeter (N.Oc/B.Pm and N.Ob/B.Pm). (F) bone formation rate over bone surface (BFR/BS) measured on bone slices from oxytetracycline and calcein green labeling of bone performed in live animals. (a) $\mathrm{p}<0.0001$; (b) $\mathrm{p}<0.001$; (c) $\mathrm{p}<0.01$; (d) $\mathrm{p}<0.05$ from OVX, determined, in F-G by 1-way ANOVA after logarithmic data transformation, which normalized the distribution of data together with homogeneous variances, or in A-B and D-E by KruskalWallis test; $n=10$ mice per group except $n=9$ in $O V X+$ vehicle group for histomorphometry.

Table 1: Effects of E197 and Zoledronate on trabecular and cortical bone in ovariectomized mice

\begin{tabular}{|c|c|c|c|c|c|}
\hline & SHAM & OVX & OVX & OVX & OVX \\
\hline & & +vehicle & $+\mathrm{ZOL}$ & +E197 q.d. & +E197 b.i.d. \\
\hline \multicolumn{6}{|c|}{ Femoral metaphysis (Histomorphometry) } \\
\hline BV/TV; \% & $17.98 \pm 4.49^{\mathrm{a}}$ & $11.67 \pm 2.37$ & $26.19 \pm 4.99^{\mathrm{a}}$ & $12.02 \pm 3.90$ & $16.83 \pm 5.55^{\mathrm{b}}$ \\
\hline Tb.Th; $\mu \mathrm{m}$ & $50.10 \pm 9.68^{b}$ & $39.96 \pm 5.42$ & $44.78 \pm 5.23$ & $41.75 \pm 8.12$ & $47.23 \pm 7.49^{c}$ \\
\hline Tb.N; $\mathrm{mm}^{-1}$ & $3.59 \pm 0.52$ & $2.99 \pm 0.80$ & $5.92 \pm 1.36^{\mathrm{c}}$ & $2.83 \pm 0.43$ & $3.51 \pm 0.81$ \\
\hline $\mathrm{Tb} . \mathrm{Sp} ; \mu \mathrm{m}$ & $235.23 \pm 53.87^{b}$ & $319.80 \pm 106.52$ & $132.16 \pm 38.01^{\mathrm{a}}$ & $318.42 \pm 58.20$ & $251.29 \pm 71.86^{\mathrm{c}}$ \\
\hline \multicolumn{6}{|c|}{ Tibial Metaphysis $(\mu \mathrm{CT})$} \\
\hline $\mathrm{BV} / \mathrm{TV} ; \%$ & $21.32 \pm 2.14^{\mathrm{b}}$ & $17.49 \pm 2.91$ & $43.96 \pm 6.08^{\mathrm{a}}$ & $19.48 \pm 2.73$ & $25.30 \pm 3.23^{\mathrm{a}}$ \\
\hline Tb.Pf; $\mu \mathrm{m} / \mathrm{d}$ & $11.19 \pm 2.52^{\mathrm{a}}$ & $17.17 \pm 3.41$ & $-35.61 \pm 7.81^{\mathrm{a}}$ & $13.69 \pm 2.90^{\mathrm{c}}$ & $6.51 \pm 2.36^{\mathrm{c}}$ \\
\hline DA; range $0-1$ & $0.46 \pm 0.04^{\mathrm{c}}$ & $0.53 \pm 0.07$ & $0.25 \pm 0.06^{\mathrm{a}}$ & $0.50 \pm 0.04$ & $0.45 \pm 0.044^{\mathrm{c}}$ \\
\hline SMI & $1.78 \pm 0.19$ & $1.92 \pm 0.19$ & $-1.36 \pm 0.71^{\mathrm{a}}$ & $1.88 \pm 0.14$ & $1.48 \pm 0.14^{\mathrm{a}}$ \\
\hline \multicolumn{6}{|c|}{ Tibial Diaphysis $(\mu \mathrm{CT})$} \\
\hline Ct.Th; $\mu \mathrm{m}$ & $187.89 \pm 6.68^{\mathrm{c}}$ & $179.27 \pm 7.57$ & $189.5 \pm 11.08^{\mathrm{c}}$ & $187.72 \pm 5.53^{\mathrm{c}}$ & $193.50 \pm 4.38^{\mathrm{a}}$ \\
\hline \multicolumn{6}{|l|}{ Serum marker } \\
\hline CTX-I; $\%{ }^{\mathrm{d}}$ & $95.14 \pm 25.34^{\mathrm{a}}$ & $165.38 \pm 54.93$ & $73.18 \pm 22.77^{\mathrm{a}}$ & $153.30 \pm 71.59$ & $112.71 \pm 30.34^{\mathrm{c}}$ \\
\hline
\end{tabular}


Effects of E197 and zoledronate on ovariectomy-induced bone loss assessed by histomorphometry in femoral metaphysis and by $\mu \mathrm{CT}$ in tibial metaphysis and diaphysis. Mice underwent ovariectomy at week 12 , treatment was started at day 0 and continued for 4 weeks. Data present mean $\pm S D, n=10$ in each group except in the OVX group for histomorphometry of femoral metaphysis $(\mathrm{n}=9)$. OVX, ovariectomized; ZOL, zoledronate; q.d., once a day; b.i.d., twice a day; BV/TV, trabecular bone volume per tissue volume; Tb.Th, trabecular thickness; Tb.N, trabecular number; Tb.Sp, trabecular separation; Tb.Pf, trabecular pattern factor; DA, Degree of anisotropy ; SMI, structure model index; Ct.Th, cortical thickness; CTX-I, serum levels of C-terminal cross-linked telopeptides of type I collagen. a, $\mathrm{p}<0.001 ; \mathrm{b}, \mathrm{p}<0.01 ; \mathrm{c}, \mathrm{p}<0.05$ from $\mathrm{OVX}$; d, relative change $\mathrm{d} 14$ to $\mathrm{d} 0$

We then analyzed the bone formation parameters by bone histomorphometry (Figure 5C). This confirmed the BV/TV results obtained by $\mu \mathrm{CT}$ (Figure 5D and Table 1). Moreover, it showed that E197 had not affect osteoclast numbers per bone perimeter (Figure 5E) and, more interestingly, osteoblast numbers per bone perimeter also remained unchanged upon E197 treatment (Table 2 and Figure 5F). In contrast, ZOL provoked a strong reduction in osteoblast numbers, as commonly observed under bisphosphonate treatments ${ }^{21}$. The mineral apposition rate and the bone formation rate per trabecular bone surface remained unaffected by E197 treatment, whereas they were strongly reduced under ZOL (Table 2 and Figure 5G). In line with these observation, the levels of osteocalcin bone turnover maker after 4 weeks of treatment was preserved under E197, contrarily to ZOL treatment, which led to lower osteocalcin concentration (Table 2). This suggests that, while preserving from OVX-induced bone loss, E197 did not affect bone formation.

Of note, E197 treatment did not affect trabecular bone geometry as illustrated in Figure 5C and Table 2. This is consistent with our previous finding that Dock5 $\mathrm{KO}$ mice have normal primary spongiosa ${ }^{26}$. Indeed, the geometry of the trabecular bone network generated by endochondral ossification is defined by the leftovers of the hypertrophic calcified cartilage after degradation by osteoclasts, which serve as templates for bone modeling ${ }^{27}$. We showed that osteoclasts do not assemble a sealing zone to resorb calcified cartilage and thus, 
endochondral ossification is not affected upon the suppression of DOCK5, even though podosomes cannot organize properly ${ }^{26}$. In contrast, under ZOL treatment, even though bone formation is strongly depressed (Figure 5G), we observed very high trabecular bone mass (Figure 5A). This illustrates the fact that bisphosphonate treatments impair mineralized cartilage resorption ${ }^{28}$. As a consequence in mice receiving ZOL, the defective resorption of calcified cartilage leads to a very dense trabecular bone network with abnormal geometry as illustrated in Figure 5C and Table 2, which was not the case with E197 treatment.

Altogether, these results suggest that DOCK5 inhibitor E197 is efficient in vivo to protect mice against pathological bone loss without affecting bone formation, whereas bisphosphonate treatment impairs the latter.

Table 2: Effects of E197 and Zoledronate on bone formation in ovariectomized mice

\begin{tabular}{|c|c|c|c|c|c|}
\hline & SHAM & OVX & OVX & OVX & OVX \\
\hline & & +vehicle & $+\mathrm{ZOL}$ & +E197 q.d. & +E197 b.i.d. \\
\hline \multicolumn{6}{|c|}{ Femoral metaphysis (Histomorphometry) } \\
\hline NB.OB/BPm; mm-1 & $4.06 \pm 1.21$ & $4.55 \pm 2.53$ & $0.54 \pm 0.67^{\mathrm{a}}$ & $2.96 \pm 2.03$ & $3.63 \pm 1.03$ \\
\hline Ob.S/BS; \% & $4.64 \pm 1.58$ & $5.03 \pm 2.92$ & $0.52 \pm 0.69^{\mathrm{a}}$ & $3.57 \pm 2.85$ & $4.01 \pm 1.26$ \\
\hline $\mathrm{MS} / \mathrm{BS} ; \%$ & $29.16 \pm 6.78$ & $27.90 \pm 8.22$ & $8.51 \pm 3.10^{\mathrm{a}}$ & $27.70 \pm 7.15$ & $26.07 \pm 4.27$ \\
\hline $\mathrm{MAR} ; \mu \mathrm{m} / \mathrm{d}(\mathrm{lcm})$ & $1.76 \pm 0.24$ & $1.62 \pm 0.21$ & $1.11 \pm 0.25^{\mathrm{a}}$ & $1.82 \pm 0.39$ & $1.65 \pm 0.24$ \\
\hline $\mathrm{BFR} / \mathrm{BS} ; \mu \mathrm{m}^{3} / \mu \mathrm{m}^{2} / \mathrm{y}$ & $188.81 \pm 56.24$ & $169.39 \pm 65.95$ & $34.28 \pm 15.11^{\mathrm{a}}$ & $184.98 \pm 64.44$ & $157.59 \pm 38.93$ \\
\hline \multicolumn{6}{|l|}{ Serum marker } \\
\hline Osteocalcin; $\%^{\mathrm{c}}$ & $90.32 \pm 63.00$ & $141.30 \pm 113.50$ & $42.55 \pm 39.09^{b}$ & $96.80 \pm 78.76$ & $109.97 \pm 83.50$ \\
\hline
\end{tabular}

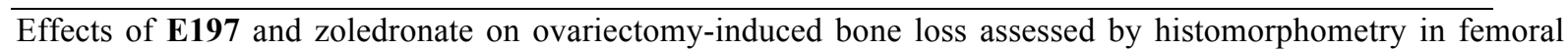
metaphysis. Mice underwent ovariectomy at week 12, treatment was started at day 0 and continued for 4 weeks. Data present mean $\pm \mathrm{SD}, \mathrm{n}=10$ in each group except for histomorphometry of femoral metaphysis $(\mathrm{n}=9)$.

OVX, ovariectomized; ZOL, zoledronate; q.d., once a day; b.i.d., twice a day; NB.OB/BPm, number of osteoblasts per bone surface; Ob.S/BS, osteoblast surface per trabecular bone surface; MS/BS, mineralizing 
surface per trabecular bone surface; MAR, mineral apposition rate; BFR/BS, bone formation rate per trabecular bone surface. a, $\mathrm{p}<0.001 ; \mathrm{b}, \mathrm{p}<0.01$ from OVX; c, relative change $\mathrm{d} 28$ to $\mathrm{d} 0$

\section{CONCLUSIONS}

In this study, we designed original $N$-arylsufonamides compounds featuring a diazaspiro[4,4]nonane nucleus that inhibit the exchange factor DOCK5, which is essential for the bone resorption activity of osteoclast. In osteoclasts, such compounds reproduced the effect of DOCK5 inhibition: they disrupted the organization of the podosome belt and prevented osteoclast resorption activity. Among these compounds, E197 protected mice from ovariectomy-induced bone loss without affecting bone formation. E197 is efficient on both mouse and human DOCK5 and can prevent both mouse and human osteoclast activity. Thus, E197 could represent a lead molecule to develop new anti-osteoporosis drugs targeting the mechanism of osteoclast adhesion onto the bone that may avoid the unwanted effects ascribed to a profound reduction in bone remodeling, such as osteonecrosis of the jaw or atypical fractures. 


\section{Experimental section.}

Synthesis of the compounds. Compounds were synthetized chemically de novo by the contract research organization (CRO) Ederlis (Lyon, France). Compounds were purified by semi preparative LC/MS to a purity higher than $95 \%$ as assessed by LC or ${ }^{1} \mathrm{H}$ NMR (Supporting Information 1\&2). MS instrument type: Waters QDA (ESI source); HPLC instrument type: Waters 2525 with « Make up » and « At column » pumps 515; Photodiode

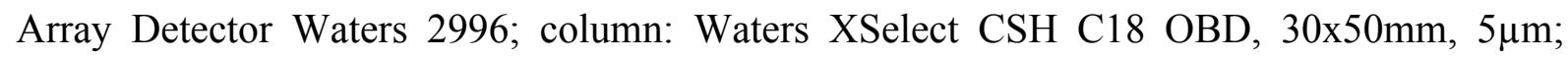
mobile phase A: $10 \mathrm{mM}$ ammonia in water, mobile phase B: acetonitrile; flow rate: 60 $\mathrm{ml} / \mathrm{min}$; injection loop volume: $2 \mathrm{~mL}$. UPLC spectra were acquired on a Waters 3100; UHPLC instrument type: Waters Acquity HClass; UV PDA e $\lambda$ Detector; column: Waters XSelect $\mathrm{C} 18 \mathrm{CSH}, 2.1 \times 50 \mathrm{~mm}, 2.5 \mu \mathrm{m}$; mobile phase A: $10 \mathrm{mM}$ ammonia in water, mobile phase B: acetonitrile; gradient: $0.0 \min 95 \% \mathrm{~A} \rightarrow 0.5 \min 95 \% \mathrm{~A} \rightarrow 3.15 \min 2 \% \mathrm{~A} \rightarrow 3.42$ $\min 2 \% \mathrm{~A} \rightarrow 3.67 \mathrm{~min} 95 \% \mathrm{~A} \rightarrow 4.0 \mathrm{~min} 95 \% \mathrm{~A}$; flow rate: $1.0 \mathrm{ml} / \mathrm{min}$; detection Thermo Corona Ultra RS. ${ }^{1} \mathrm{H}$ NMR spectra (Supporting information 3) were recorded on a Bruker AVANCE 500 NMR Spectrometer equipped with a Bruker 5 mm PABBO BB-1H/D Z-GRD at $500 \mathrm{MHz}$ for proton NMR (Supporting Information 3). Chemical shifts are reported in ppm $(\delta)$. Data are reported as follows: chemical shifts $(\delta)$, multiplicity $(b=$ broad, $s=$ singlet, $d=$ doublet, $\mathrm{t}=$ triplet, $\mathrm{q}=$ quartet, quint $=$ quintuplet, $\mathrm{m}=$ multiplet $)$, coupling constants $(\mathrm{J})$ in $\mathrm{Hz}$, integration.

Detailed synthesis of compounds E196, E197, E202, E203, E204, E205, E210, E211 (Scheme 1)

$\underline{N \text {-(2,2-diethoxyethyl)- } N \text {-phenylethenesulfonamide }}$ 
2-chloroethane-1-sulfonyl chloride $(13.07 \mathrm{~mL}, 124.2 \mathrm{mmol})$ was added to a cooled $\left(0^{\circ} \mathrm{C}\right)$ solution of $N$-(2,2-diethoxyethyl)aniline $1(20.0 \mathrm{~g}, 95.5 \mathrm{mmol})$ and triethylamine $(39.96 \mathrm{~mL}$, $286.7 \mathrm{mmol}$ ) in $1 \mathrm{~L}$ of 1,2-dichloroethane (DCE). The reaction mixture was stirred at room temperature overnight. The suspension was filtered and the organic layer was washed with saturated aqueous sodium bicarbonate, with aqueous $\mathrm{HCl} 1 \mathrm{~N}$, with brine, dried over sodium sulphate, filtered and the filtrate was concentrated under vacuum to afford title compound (28.4 g, 99\%, brown oil). ${ }^{1} \mathrm{H}$ NMR (500 MHz, $\left.\mathrm{CDCl}_{3}\right): \delta$ 7.41-7.29 (m, 5H), $6.58(\mathrm{dd}, J=$ 16.6, 9.9 Hz, 1H), $6.16(\mathrm{~d}, J=16.6 \mathrm{~Hz}, 1 \mathrm{H}), 5.94(\mathrm{~d}, J=9.9 \mathrm{~Hz}, 1 \mathrm{H}), 4.61(\mathrm{t}, J=5.5 \mathrm{~Hz}, 1 \mathrm{H})$, $3.69(\mathrm{~d}, J=5.5 \mathrm{~Hz}, 2 \mathrm{H}), 3.63(\mathrm{~m}, 2 \mathrm{H}), 3.49(\mathrm{~m}, 2 \mathrm{H}), 1.14(\mathrm{t}, J=7.0 \mathrm{~Hz}, 6 \mathrm{H})$.

$\underline{N \text {-(2-oxoethyl)- } N \text {-phenylethenesulfonamide }}$

A solution of $N$-(2,2-diethoxyethyl)- $N$-phenylethenesulfonamide $2(28.4 \mathrm{~g}, 94.9 \mathrm{mmol})$ was stirred for three days in a mixture of acetic acid $(200 \mathrm{~mL})$, tetrahydrofuran (THF) $(200 \mathrm{~mL})$ and $10 \%$ aqueous $\mathrm{HCl}(400 \mathrm{~mL})$. The solution was poured onto EA and the two phases were separated. The organic layer was washed with water, with brine, dried over sodium sulphate, filtered and the filtrate was concentrated under vacuum. Purification of the residue by flash chromatography on silica gel (cyclohexane-ethyl acetate (cHx-EA) 1/1) afforded the title compound (15.30 g, 71\%, orange oil). ${ }^{1} \mathrm{H} \mathrm{NMR}\left(500 \mathrm{MHz}, \mathrm{CDCl}_{3}\right): \delta 9.69(\mathrm{~s}, 1 \mathrm{H}), 7.40-7.30$ (m, 5H), $6.66(\mathrm{dd}, J=16.6,9.9 \mathrm{~Hz}, 1 \mathrm{H}), 6.16(\mathrm{~d}, J=16.6 \mathrm{~Hz}, 1 \mathrm{H}), 5.99(\mathrm{~d}, J=9.9 \mathrm{~Hz}, 1 \mathrm{H})$, $4.41(\mathrm{~s}, 2 \mathrm{H})$

\section{4-((tert-butyldimethylsilyl)oxy)-5-methylene-2-phenylisothiazolidine 1,1-dioxide}

A solution of $N$-(2-oxoethyl)- $N$-phenylethenesulfonamide $3(15.28 \mathrm{~g}, 67.8 \mathrm{mmol})$ and 1,4diazabicyclo[2.2.2] octane $(0.76 \mathrm{~g}, 6.8 \mathrm{mmol})$ in dichloromethane $(310 \mathrm{~mL})$ was stirred for two hours at room temperature. Then imidazole $(6.47 \mathrm{~g}, 95.0 \mathrm{mmol})$ followed by tertbutyldimethylsilyl chloride (14.31 g, $95.0 \mathrm{mmol})$ were added. After two hours of stirring, additional imidazole $(0.46 \mathrm{~g}, 6.8 \mathrm{mmol})$ and tert-butyldimethylsilyl chloride $(1.02 \mathrm{~g}, 6.8$ 
mmol) were added. Once the conversion complete, the suspension was filtered off and the filtrate was concentrated under vacuum. Purification of the residue by flash chromatography on silica gel (cHx-EA) afforded the title compound (15.2 g, 66\%, orange oil). ${ }^{1} \mathrm{H}$ NMR (500 $\left.\mathrm{MHz}, \mathrm{CDCl}_{3}\right): \delta 7.38(\mathrm{~m}, 2 \mathrm{H}), 7.34-7.30(\mathrm{~m}, 2 \mathrm{H}), 7.23-7.18(\mathrm{~m}, 1 \mathrm{H}), 6.23(\mathrm{~m}, 1 \mathrm{H}), 5.87(\mathrm{dd}$, $J=2.5,1.7 \mathrm{~Hz}, 1 \mathrm{H}), 5.11(\mathrm{tt}, J=7.3,2.5 \mathrm{~Hz}, 1 \mathrm{H}), 3.86(\mathrm{dd}, J=8.4,7.2 \mathrm{~Hz}, 1 \mathrm{H}), 3.53(\mathrm{dd}, J=$ 8.4, $7.5 \mathrm{~Hz}, 1 \mathrm{H}), 0.96(\mathrm{~s}, 9 \mathrm{H}), 0.19$ (s, 3H), 0.18 (s, 3H).

rac-(4S,5R)-7-benzyl-4-((tert-butyldimethylsilyl)oxy)-2-phenyl-1-thia-2,7diazaspiro[4.4]nonane 1,1-dioxide

Trifluoroacetic acid (333 $\mu \mathrm{L}, 4.49 \mathrm{mmol})$ was added to a solution of 4-((tertbutyldimethylsilyl)oxy)-5-methylene-2-phenylisothiazolidine 1,1-dioxide 4 (15.25 g, 44.92 mmol) and $N$-(methoxymethyl)- $N$-(trimethylsilylmethyl)benzylamine $(17.24 \mathrm{~mL}, 67.37$ mmol). The resulting solution was stirred at $45^{\circ} \mathrm{C}$ overnight. After cooling to room temperature, the organic layer was washed with saturated aqueous sodium bicarbonate, with brine, dried over sodium sulphate, filtered and the filtrate was concentrated under vacuum. Purification of the residue by flash chromatography on silica gel (cHx-EA 9/1 to 75/25) afforded the title compound $(8.17 \mathrm{~g}, 38 \%$, yellow oil) and its diastereoisomer $(8.10 \mathrm{~g}, 38 \%$, yellow oil). ${ }^{1} \mathrm{H}$ NMR $\left(500 \mathrm{MHz}, \mathrm{CDCl}_{3}\right): \delta 7.38-7.28(\mathrm{~m}, 6 \mathrm{H}), 7.26-7.21(\mathrm{~m}, 3 \mathrm{H}), 7.12(\mathrm{tt}, J=$ 7.3, $1.1 \mathrm{~Hz}, 1 \mathrm{H}), 4.55(\mathrm{dd}, J=7.8,6.7 \mathrm{~Hz}, 1 \mathrm{H}), 3.70-3.64(\mathrm{~m}, 3 \mathrm{H}), 3.43-3.38(\mathrm{~m}, 2 \mathrm{H}), 2.88$ $(\mathrm{td}, J=8.1,5.6 \mathrm{~Hz}, 1 \mathrm{H}), 2.68(\mathrm{~d}, J=11.0 \mathrm{~Hz}, 1 \mathrm{H}), 2.66-2.59(\mathrm{~m}, 1 \mathrm{H}), 2.52-2.37(\mathrm{~m}, 2 \mathrm{H})$, $0.93(\mathrm{~s}, 9 \mathrm{H}), 0.12(\mathrm{~s}, 3 \mathrm{H}), 0.11(\mathrm{~s}, 3 \mathrm{H})$.

rac-(4S,5R)-7-benzyl-4-hydroxy-2-phenyl-1-thia-2,7-diazaspiro[4.4]nonane 1,1-dioxide A solution of tetrabutylammonium fluoride (1M in THF, $20.74 \mathrm{mmol}, 20.74 \mathrm{~mL}$ ) was added to a solution of Rac-(4S,5R)-7-benzyl-4-((tert-butyldimethylsilyl)oxy)-2-phenyl-1-thia-2,7diazaspiro[4.4]nonane 1,1-dioxide $5(8.17 \mathrm{~g}, 17.28 \mathrm{mmol})$ in THF $(170 \mathrm{~mL})$. After complete consumption of starting material, the medium was concentrated under reduced pressure. 
Purification of the residue by flash chromatography on silica gel (cHx/EA: 1/0 to 0/1) afforded the title compound (4.32 g, 70\%, orange solid). ${ }^{1} \mathrm{H}$ NMR (500 $\left.\mathrm{MHz}, \mathrm{CDCl}_{3}\right): \delta 7.38$ $7.26(\mathrm{~m}, 7 \mathrm{H}), 7.25-7.20(\mathrm{~m}, 2 \mathrm{H}), 7.14(\mathrm{tt}, J=7.4,1.1 \mathrm{~Hz}, 1 \mathrm{H}), 4.56(\mathrm{dd}, J=6.3,5.2 \mathrm{~Hz}, 1 \mathrm{H})$, $3.87(\mathrm{dd}, J=9.3,6.3 \mathrm{~Hz}, 1 \mathrm{H}), 3.71(\mathrm{~d}, J=12.9 \mathrm{~Hz}, 1 \mathrm{H}), 3.64(\mathrm{~d}, J=12.9 \mathrm{~Hz}, 1 \mathrm{H}), 3.56$ (dd, $J$ $=9.3,5.2 \mathrm{~Hz}, 1 \mathrm{H}), 3.07(\mathrm{~d}, J=10.0 \mathrm{~Hz}, 1 \mathrm{H}), 3.00(\mathrm{td}, J=8.5,3.8 \mathrm{~Hz}, 1 \mathrm{H}), 2.90(\mathrm{~d}, J=10.0$ Hz, 1H), 2.65 (m, 1H), 2.53 (m, 1H), 2.44 (ddd, $J=13.9,8.8,3.8 \mathrm{~Hz}, 1 \mathrm{H})$. rac-(4S,5R)-4-hydroxy-2-phenyl-1-thia-2,7-diazaspiro[4.4]nonane 1,1-dioxide A solution of Rac-(4S,5R)-7-benzyl-4-hydroxy-2-phenyl-1-thia-2,7-diazaspiro[4.4]nonane 1,1-dioxide $6(1.80 \mathrm{~g}, 5.02 \mathrm{mmmol})$ in a mixture of EtOH $(90 \mathrm{~mL})$ and acetic acid $(10 \mathrm{~mL})$ was hydrogenated using Palladium $(\mathrm{Pd} / \mathrm{C} 10 \%)$ as catalyst in a ThalesNano, $\mathrm{H}$-cube ${ }^{\circledR}$ system (40 bars, $40^{\circ} \mathrm{C}, \mathrm{H}_{2}$, flow rate of $0.8 \mathrm{~mL} / \mathrm{min}$ ). Concentration of the resulting solution and purification of the residue by filtration on silica gel $\left(\mathrm{CH}_{3} \mathrm{CN}-\mathrm{aqNH} \mathrm{H}_{3} 100 \%\right.$ to $\left.95 / 5\right)$ afforded the title compound as a white solid (0.93 g, 69\%). ${ }^{1} \mathrm{H}$ NMR (500 MHz, DMSO- $\left.d_{6}\right): \delta 7.41-$ $7.33(\mathrm{~m}, 2 \mathrm{H}), 7.25-7.16(\mathrm{~m}, 2 \mathrm{H}), 7.10(\mathrm{tt}, J=7.4,1.1 \mathrm{~Hz}, 1 \mathrm{H}), 6.09$ (d, $J=4.9 \mathrm{~Hz}, 1 \mathrm{H}), 4.39$ $(\mathrm{td}, J=6.1,4.9 \mathrm{~Hz}, 1 \mathrm{H}), 3.84(\mathrm{dd}, J=9.1,6.1 \mathrm{~Hz}, 1 \mathrm{H}), 3.44(\mathrm{dd}, J=9.1,6.1 \mathrm{~Hz}, 1 \mathrm{H}), 3.38$ (d, $J=12.6 \mathrm{~Hz}, 1 \mathrm{H}), 2.98(\mathrm{~d}, J=12.6 \mathrm{~Hz}, 1 \mathrm{H}), 2.93$ (ddd, $J=10.9,7.7,5.8 \mathrm{~Hz}, 1 \mathrm{H}), 2.85$ (ddd, $J=10.9,7.5,6.3 \mathrm{~Hz}, 1 \mathrm{H}), 2.29(\mathrm{ddd}, J=13.4,7.5,5.8 \mathrm{~Hz}, 1 \mathrm{H}), 2.06$ (ddd, $J=13.7,7.7$, $6.3 \mathrm{~Hz}, 1 \mathrm{H})$. HRMS (ESI, $m / z)$ calcd for C12H17N2O3S $[\mathrm{M}+\mathrm{H}]+, 269,0954$; found, 269,0953 (ORBITRAP MS ES+)

\section{Typical procedure for reductive amination}

A suspension of rac-(4S,5R)-4-hydroxy-2-phenyl-1-thia-2,7-diazaspiro[4.4]nonane 1,1dioxide $7(0.175 \mathrm{mmol})$ and the aldehyde/ketone $(0.21 \mathrm{mmol}, 1.2 \mathrm{eq})$ in THF $(1 \mathrm{~mL})$ was stirred at room temperature for 30 minutes. Sodium triacetoxyborohydride $(0.385 \mathrm{mmol}, 2.2$ eq) was then added and the resulting mixture was stirred at room temperature overnight. The medium was treated with water $(100 \mu \mathrm{L})$, the suspension was filtered and the filtrate was 
concentrated under reduced pressure. Purification of the residue by preparative RP-HPLC (Puriflash) afforded desired compound. The following compounds are obtained by synthesis process described above:

rac-(4S,5R)-7-(3-chlorobenzyl)-4-hydroxy-2-phenyl-1-thia-2,7-diazaspiro[4.4]nonane 1,1-dioxide (E73)

UPLC-MS (m/z): 393.1-395.2 [M+H] ${ }^{+} .{ }^{1} \mathrm{H}$ NMR (400 MHz, DMSO- $\left.d_{6}\right): \delta 7.44-7.26(\mathrm{~m}$, $6 \mathrm{H}), 7.21(\mathrm{~d}, J=7.8 \mathrm{~Hz}, 2 \mathrm{H}), 7.11(\mathrm{t}, J=7.4 \mathrm{~Hz}, 1 \mathrm{H}), 6.23(\mathrm{~d}, J=5.3 \mathrm{~Hz}, 1 \mathrm{H}), 4.38(\mathrm{q}, J=$ $6.3 \mathrm{~Hz}, 1 \mathrm{H}), 3.80(\mathrm{dd}, J=9.0,6.3 \mathrm{~Hz}, 1 \mathrm{H}), 3.64(\mathrm{q}, J=13.7 \mathrm{~Hz}, 2 \mathrm{H}), 3.43(\mathrm{dd}, J=9.1,7.0$ $\mathrm{Hz}, 1 \mathrm{H}), 3.28-3.20(\mathrm{~m}, 2 \mathrm{H}), 2.91-2.80(\mathrm{~m}, 1 \mathrm{H}), 2.65(\mathrm{~d}, J=10.9 \mathrm{~Hz}, 1 \mathrm{H}), 2.47-2.34(\mathrm{~m}$, $1 \mathrm{H}), 2.22(\mathrm{dt}, J=14.0,7.4 \mathrm{~Hz}, 1 \mathrm{H}) .{ }^{13} \mathrm{C}$ NMR (100.62 MHz, DMSO- $\left.d_{6}\right): \delta 141.18,137.96$, $132.95,130.09,129.15,128.01,126.91,123.38,118.40,70.58,66.70,57.71,57.29,53.13$, 50.75, 25.48. HRMS (ESI, $m / z$ ) calcd for $\mathrm{C}_{19} \mathrm{H}_{22} \mathrm{ClN}_{2} \mathrm{O}_{3} \mathrm{~S}[\mathrm{M}+\mathrm{H}]^{+}$393.1034, found 393.1032 (ORBITRAP MS ES $\left.{ }^{+}\right)$

rac-(4S,5R)-7-(2-chlorobenzyl)-4-hydroxy-2-phenyl-1-thia-2,7-diazaspiro[4.4]nonane

\section{1,1-dioxide (E196)}

UPLC-MS (m/z): 393.1-395.2 $[\mathbf{M}+\mathbf{H}]^{+} .{ }^{1} \mathrm{H}$ NMR (500 MHz, DMSO- $\left.d_{6}\right): \delta 7.54(\mathrm{dd}, J=7.6$, $1.8 \mathrm{~Hz}, 1 \mathrm{H}), 7.43(\mathrm{dd}, J=7.9,1.4 \mathrm{~Hz}, 1 \mathrm{H}), 7.38-7.33(\mathrm{~m}, 3 \mathrm{H}), 7.29(\mathrm{td}, J=7.6,1.9 \mathrm{~Hz}, 1 \mathrm{H})$, 7.22-7.20 (m, 2H), $7.11(\mathrm{tt}, J=7.4,1.1 \mathrm{~Hz}, 1 \mathrm{H}), 6.25(\mathrm{~s}, 1 \mathrm{H}), 4.39(\mathrm{t}, J=6.7 \mathrm{~Hz}, 1 \mathrm{H}), 3.81$ $(\mathrm{dd}, J=9.1,6.3 \mathrm{~Hz}, 1 \mathrm{H}), 3.77(\mathrm{~d}, J=14.3 \mathrm{~Hz}, 1 \mathrm{H}), 3.72(\mathrm{~d}, J=14.3 \mathrm{~Hz}, 1 \mathrm{H}), 3.44(\mathrm{dd}, J=$ 9.0, $7.0 \mathrm{~Hz}, 1 \mathrm{H}), 3.34(\mathrm{~d}, J=10.7 \mathrm{~Hz}, 1 \mathrm{H}), 2.92(\mathrm{td}, J=8.2,4.2 \mathrm{~Hz}, 1 \mathrm{H}), 2.71(\mathrm{~d}, J=10.8$ $\mathrm{Hz}, 1 \mathrm{H}), 2.54(\mathrm{q}, J=7.9 \mathrm{~Hz}, 1 \mathrm{H}), 2.41(\mathrm{ddd}, J=13.6,7.7,4.2 \mathrm{~Hz}, 1 \mathrm{H}), 2.23(\mathrm{dt}, J=13.6,7.7$ $\mathrm{Hz}, 1 \mathrm{H})$.

rac-(4S,5R)-7-(4-chlorobenzyl)-4-hydroxy-2-phenyl-1-thia-2,7-diazaspiro[4.4]nonane 1,1-dioxide (E197) 
UPLC-MS (m/z): 393.1-395.2 $[\mathbf{M}+\mathbf{H}]^{+} .{ }^{1} \mathrm{H}$ NMR (500 MHz, DMSO- $\left.d_{6}\right) \delta$ 7.41-7.33 (m, 6H), $7.20(\mathrm{dt}, J=7.9,1.1 \mathrm{~Hz}, 2 \mathrm{H}), 7.12-7.08(\mathrm{~m}, 1 \mathrm{H}), 6.23(\mathrm{bs}, 1 \mathrm{H}), 4.37(\mathrm{t}, J=6.8 \mathrm{~Hz}, 1 \mathrm{H})$, $3.80(\mathrm{dd}, J=9.0,6.4 \mathrm{~Hz}, 1 \mathrm{H}), 3.64(\mathrm{~d}, J=13.4 \mathrm{~Hz}, 1 \mathrm{H}), 3.58(\mathrm{~d}, J=13.4 \mathrm{~Hz}, 1 \mathrm{H}), 3.42(\mathrm{dd}, J$ $=9.0,7.0 \mathrm{~Hz}, 1 \mathrm{H}), 3.24(\mathrm{~d}, J=10.8 \mathrm{~Hz}, 1 \mathrm{H}), 2.84(\mathrm{td}, J=8.2,4.2 \mathrm{~Hz}, 1 \mathrm{H}), 2.63(\mathrm{~d}, J=10.8$ Hz, 1H), 2.45 (m, 1H), 2.43-2.34 (m, 1H), $2.21(\mathrm{dt}, J=13.6,7.5 \mathrm{~Hz}, 1 \mathrm{H})$. HRMS (ESI, $m / z)$ calcd for C19H22CIN2O3S [M+H]+ 393.1034, found 393.1032 (ORBITRAP MS ES+)

rac-(4S,5R)-7-(3,4-dichlorobenzyl)-4-hydroxy-2-phenyl-1-thia-2,7-diazaspiro[4.4]nonane 1,1-dioxide (E202)

UPLC-MS (m/z): 427.1-429.1 $[\mathbf{M}+\mathbf{H}]^{+} .{ }^{1} \mathrm{H}$ NMR $\left(500 \mathrm{MHz}\right.$, DMSO- $\left.d_{6}\right) \delta$ 7.62-7.56 (m, 2H), 7.40-7.30 (m, 3H), 7.23-7.19 (m, 2H), $7.11(\mathrm{tt}, J=7.3,1.1 \mathrm{~Hz}, 1 \mathrm{H}), 6.23(\mathrm{bs}, 1 \mathrm{H}), 4.38$ (t, $J=6.6 \mathrm{~Hz}, 1 \mathrm{H}), 3.80(\mathrm{dd}, J=9.0,6.3 \mathrm{~Hz}, 1 \mathrm{H}), 3.67(\mathrm{~d}, J=13.8 \mathrm{~Hz}, 1 \mathrm{H}), 3.61(\mathrm{~d}, J=13.8$ $\mathrm{Hz}, 1 \mathrm{H}), 3.43(\mathrm{dd}, J=9.0,7.0 \mathrm{~Hz}, 1 \mathrm{H}), 3.25(\mathrm{~d}, J=10.8 \mathrm{~Hz}, 1 \mathrm{H}), 2.85(\mathrm{td}, J=8.2,4.2 \mathrm{~Hz}$, $1 \mathrm{H}), 2.65(\mathrm{~d}, J=10.8 \mathrm{~Hz}, 1 \mathrm{H}), 2.47(\mathrm{~m}, 1 \mathrm{H}), 2.40(\mathrm{ddd}, J=13.6,7.8,4.3 \mathrm{~Hz}, 1 \mathrm{H}), 2.22(\mathrm{dt}, J$ $=13.5,7.6 \mathrm{~Hz}, 1 \mathrm{H})$.

rac-(4S,5R)-4-hydroxy-2-phenyl-7-(quinolin-3-ylmethyl)-1-thia-2,7-

diazaspiro[4.4]nonane 1,1-dioxide (E203)

UPLC-MS (m/z): $410.2[\mathbf{M}+\mathbf{H}]^{+} .{ }^{1} \mathrm{H}$ NMR $\left(500 \mathrm{MHz}, \mathrm{DMSO}-d_{6}\right) \delta 8.88(\mathrm{~d}, J=2.1 \mathrm{~Hz}, 1 \mathrm{H})$, $8.25(\mathrm{~d}, J=1.4 \mathrm{~Hz}, 1 \mathrm{H}), 8.01(\mathrm{~d}, J=8.4 \mathrm{~Hz}, 1 \mathrm{H}), 7.96(\mathrm{dd}, J=8.3,1.1 \mathrm{~Hz}, 1 \mathrm{H}), 7.74(\mathrm{ddd}, J$ $=8.4,6.9,1.5 \mathrm{~Hz}, 1 \mathrm{H}), 7.61(\mathrm{ddd}, J=8.1,6.8,1.2 \mathrm{~Hz}, 1 \mathrm{H}), 7.41-7.31(\mathrm{~m}, 2 \mathrm{H}), 7.23-7.17(\mathrm{~m}$, 2H), $7.10(\mathrm{tt}, J=7.5,1.1 \mathrm{~Hz}, 1 \mathrm{H}), 6.25(\mathrm{~s}, 1 \mathrm{H}), 4.38(\mathrm{t}, J=6.6 \mathrm{~Hz}, 1 \mathrm{H}), 3.87(\mathrm{~d}, J=13.5 \mathrm{~Hz}$, $1 \mathrm{H}), 3.83(\mathrm{~d}, J=13.5 \mathrm{~Hz}, 1 \mathrm{H}), 3.79(\mathrm{dd}, J=9.0,6.2 \mathrm{~Hz}, 1 \mathrm{H}), 3.43(\mathrm{dd}, J=9.0,7.0 \mathrm{~Hz}, 1 \mathrm{H})$, $3.28(\mathrm{~d}, J=10.9 \mathrm{~Hz}, 1 \mathrm{H}), 2.90(\mathrm{td}, J=8.1,4.6 \mathrm{~Hz}, 1 \mathrm{H}), 2.73(\mathrm{~d}, J=10.9 \mathrm{~Hz}, 1 \mathrm{H}), 2.58(\mathrm{q}, J$ $=7.6 \mathrm{~Hz}, 1 \mathrm{H}), 2.43(\mathrm{ddd}, J=12.3,7.6,4.6 \mathrm{~Hz}, 1 \mathrm{H}), 2.29-2.19(\mathrm{~m}, 1 \mathrm{H})$. 
rac-(4S,5R)-4-hydroxy-7-((1-methyl-1H-indol-3-yl)methyl)-2-phenyl-1-thia-2,7diazaspiro[4.4]nonane 1,1-dioxide (E204)

UPLC-MS (m/z): $412.2[\mathbf{M}+\mathbf{H}]^{+} .{ }^{1} \mathrm{H}$ NMR $\left(500 \mathrm{MHz}, \mathrm{DMSO}-d_{6}\right) \delta 7.64(\mathrm{dt}, J=7.9,1.0 \mathrm{~Hz}$, 1H), 7.40-7.32 (m, 3H), 7.24 (s, 1H), 7.21-7.17 (m, 2H), 7.14 (ddd, $J=8.2,7.0,1.2 \mathrm{~Hz}, 1 \mathrm{H})$, 7.09 (tt, $J=7.4,1.1 \mathrm{~Hz}, 1 \mathrm{H}), 7.02(\mathrm{ddd}, J=8.0,7.0,1.0 \mathrm{~Hz}, 1 \mathrm{H}), 6.20(\mathrm{bs}, 1 \mathrm{H}), 4.35$ (m, 1H), $3.78(\mathrm{dd}, J=9.1,6.4 \mathrm{~Hz}, 1 \mathrm{H}), 3.73(\mathrm{~s}, 5 \mathrm{H}), 3.41(\mathrm{dd}, J=9.0,7.0 \mathrm{~Hz}, 1 \mathrm{H}), 3.27$ (d, $J=10.9$ $\mathrm{Hz}, 1 \mathrm{H}), 2.83(\mathrm{td}, J=8.2,4.4 \mathrm{~Hz}, 1 \mathrm{H}), 2.69(\mathrm{~d}, J=10.8 \mathrm{~Hz}, 1 \mathrm{H}), 2.50(\mathrm{~m}, 1 \mathrm{H}), 2.36(\mathrm{ddd}, J=$ 13.6, 7.6, 4.4 Hz, 1H), $2.18(\mathrm{dt}, J=13.5,7.5 \mathrm{~Hz}, 1 \mathrm{H})$.

rac-(4S,5R)-7-((2,3-dihydro-1H-inden-5-yl)methyl)-4-hydroxy-2-phenyl-1-thia-2,7diazaspiro[4.4]nonane 1,1-dioxide (E210)

UPLC-MS (m/z): $399.2[\mathbf{M}+\mathbf{H}]^{+} .{ }^{1} \mathrm{H}$ NMR (500 MHz, DMSO- $\left.d_{6}\right) \delta$ 7.40-7.32 (m, 2H), 7.22$7.17(\mathrm{~m}, 2 \mathrm{H}), 7.17-7.14(\mathrm{~m}, 2 \mathrm{H}), 7.13-7.08(\mathrm{~m}, 1 \mathrm{H}), 7.06(\mathrm{~d}, J=7.7 \mathrm{~Hz}, 1 \mathrm{H}), 6.22(\mathrm{bs}, 1 \mathrm{H})$, $4.36(\mathrm{t}, J=6.7 \mathrm{~Hz}, 1 \mathrm{H}), 3.79(\mathrm{dd}, J=9.0,6.3 \mathrm{~Hz}, 1 \mathrm{H}), 3.60(\mathrm{~d}, J=12.9 \mathrm{~Hz}, 1 \mathrm{H}), 3.52(\mathrm{~d}, J=$ $12.9 \mathrm{~Hz}, 1 \mathrm{H}), 3.42(\mathrm{dd}, J=9.0,7.1 \mathrm{~Hz}, 1 \mathrm{H}), 3.24(\mathrm{~d}, J=10.8 \mathrm{~Hz}, 1 \mathrm{H}), 2.83(\mathrm{~m}, 5 \mathrm{H}), 2.62(\mathrm{~d}$, $J=10.9 \mathrm{~Hz}, 1 \mathrm{H}), 2.45(\mathrm{q}, J=7.6 \mathrm{~Hz}, 1 \mathrm{H}), 2.38(\mathrm{ddd}, J=12.0,7.6,4.2 \mathrm{~Hz}, 1 \mathrm{H}), 2.19(\mathrm{dt}, J=$ 13.4, $7.5 \mathrm{~Hz}, 1 \mathrm{H}$ ), 2.00 (quint, $J=7.4 \mathrm{~Hz}, 2 \mathrm{H}$ ).

rac-(4S,5R)-7-(3-fluoro-4-methoxybenzyl)-4-hydroxy-2-phenyl-1-thia-2,7diazaspiro[4.4]nonane 1,1-dioxide (E211)

UPLC-MS (m/z): $407.2[\mathrm{M}+\mathrm{H}]+$. No ${ }^{1} \mathrm{H}$ NMR data available due to low amounts of the compound. See supporting Information 1 and 2 for LC and MS spectra of E211.

Synthesis of compounds E226, E228 (Scheme 2) 


\section{rac-7-benzyl-2-(3-fluorophenyl)-2,7-diazaspiro[4.4]nonan-1-one (9a)}

Compound 8 (6.5 g, $28 \mathrm{mmol})$ and $N, N^{\prime}$-dimethylethylene diamine (15 mol\%) were dissolved in a flask then dioxane $(60 \mathrm{~mL})$ was added. An argon stream was passed through the white suspension for 10 minutes. In the reaction flask, $\mathrm{CuI}(15 \mathrm{~mol} \%), \mathrm{K}_{3} \mathrm{PO}_{4}$ (3 eq.) and 1-bromo3-fluorobenzene (1 eq.) were weighed out and place under argon atmosphere. The solution was added and the resulting blue suspension was heated at reflux for $2 \mathrm{~h}$ (turning white) then at $90^{\circ} \mathrm{C} \mathrm{o} / \mathrm{n}$. Additional $N, N^{\prime}$-dimethylethylene diamine $(7 \mathrm{~mol} \%)$ and $\mathrm{CuI}(7 \mathrm{~mol} \%)$ were added and the resulting suspension was heated at reflux for $5 \mathrm{~h}$ then left to stir at $90^{\circ} \mathrm{C} \mathrm{o} / \mathrm{n}$. The mixture was then cooled down to rt, filtered through a pad of Celite, washed with EtOAc and DCM, concentrated in vacuo. The residue was purified by flash column chromatography (cHexane-EtOAc, $1 / 0$ to $0 / 1)$ to afford compound $9 \mathbf{a}(6.8 \mathrm{~g}, 74 \%)$ as a white crystalline solid.

UPLC-MS (m/z): $325.3[\mathbf{M}+\mathbf{H}]^{+} .{ }^{1} \mathrm{H}$ NMR $\left(500 \mathrm{MHz}, \mathrm{DMSO}-d_{6}\right) \delta 7.67(\mathrm{dt}, J=12.1,2.2$ $\mathrm{Hz}, 1 \mathrm{H}), 7.46-7.37(\mathrm{~m}, 2 \mathrm{H}), 7.35-7.28(\mathrm{~m}, 4 \mathrm{H}), 7.27-7.21(\mathrm{~m}, 1 \mathrm{H}), 6.96(\mathrm{dddd}, J=9.1$, 8.2, 2.6, 1.3 Hz, 1H), $3.75(\mathrm{t}, J=6.7 \mathrm{~Hz}, 2 \mathrm{H}), 3.61(\mathrm{~s}, 2 \mathrm{H}), 2.83-2.75(\mathrm{~m}, 1 \mathrm{H}), 2.68(\mathrm{~d}, J=$ $9.1 \mathrm{~Hz}, 1 \mathrm{H}), 2.55(\mathrm{~d}, J=9.1 \mathrm{~Hz}, 1 \mathrm{H}), 2.49-2.43(\mathrm{~m}, 1 \mathrm{H}), 2.21-2.03(\mathrm{~m}, 3 \mathrm{H}), 1.78(\mathrm{dt}, J=$ 12.6, 7.2 Hz, 1H).

\section{rac-2-(3-fluorophenyl)-2,7-diazaspiro[4.4]nonan-1-one (10a)}

1-chloroethyl carbonochloridate $(2.93 \mathrm{~mL}, 1.3$ eq.) was added to a solution of 9a (6.8 g, 21 $\mathrm{mmol})$ in DCE $(75 \mathrm{~mL}, 0.28 \mathrm{M})$. The reaction mixture was stirred at $80^{\circ} \mathrm{C}$ for $2 \mathrm{~h}$. Additional 1-chloroethyl carbonochloridate $(0.1 \mathrm{~mL})$ was added to the reaction mixture and stirred for further $1 \mathrm{~h}$. The reaction mixture was then concentrated. The residue was diluted in $\mathrm{MeOH}(70$ $\mathrm{mL}$ ) and stirred at $60^{\circ} \mathrm{C}$ for $2 \mathrm{~h}$ (gas evolution). The reaction mixture was concentrated, diluted with DCM and washed with conc. $\mathrm{NaOH}$ aqueous solution ( $\mathrm{pH} \sim 14)$. The organic layer was concentrated to give compound 10a $(4.5 \mathrm{~g}, 91 \%)$. 
UPLC-MS (m/z): $235.2[\mathbf{M}+\mathbf{H}]^{+} .{ }^{1} \mathrm{H}$ NMR $\left(500 \mathrm{MHz}, \mathrm{CDCl}_{3}\right) \delta 7.54(\mathrm{dt}, J=11.5,2.3 \mathrm{~Hz}$, 1H), $7.38-7.27(\mathrm{~m}, 2 \mathrm{H}), 6.83(\mathrm{tdd}, J=8.1,2.5,1.2 \mathrm{~Hz}, 1 \mathrm{H}), 3.77(\mathrm{t}, J=7.0 \mathrm{~Hz}, 2 \mathrm{H}), 3.32(\mathrm{~d}$, $J=11.6 \mathrm{~Hz}, 1 \mathrm{H}), 3.27-3.18(\mathrm{~m}, 1 \mathrm{H}), 3.06-2.97(\mathrm{~m}, 1 \mathrm{H}), 2.85(\mathrm{~d}, J=11.6 \mathrm{~Hz}, 1 \mathrm{H}), 2.26-$ $2.14(\mathrm{~m}, 3 \mathrm{H}), 1.82(\mathrm{ddd}, J=12.6,7.7,4.8 \mathrm{~Hz}, 1 \mathrm{H})$.

\section{rac-7-benzyl-2-(4-methoxy-3-methylphenyl)-2,7-diazaspiro[4.4]nonan-1-one (9b)}

Compound 8 (5.7 g, $25 \mathrm{mmol})$ and $N, N^{\prime}$-dimethylethylene diamine (15 mol\%) were dissolved in a flask then dioxane $(55 \mathrm{~mL}, 0.45 \mathrm{M})$ was added. An argon stream was passed through the white suspension for $10 \mathrm{~min}$. In the reaction flask, $\mathrm{CuI}(15 \mathrm{~mol} \%), \mathrm{K}_{3} \mathrm{PO}_{4}$ (3 eq.) and 4bromo-1-methoxy-2-methylbenzene (1.05 eq.) were weighed out and placed under argon atmosphere. The solution was added and the resulting blue suspension was heated at reflux for $2 \mathrm{~h}$ (turning white) then at $90^{\circ} \mathrm{C} \mathrm{o} / \mathrm{n} . N, N^{\prime}$-dimethylethylene diamine $(7 \mathrm{~mol} \%)$ and $\mathrm{CuI}(7$ mol\%) were added and the resulting suspension was heated at reflux for $5 \mathrm{~h}$ then left to stir at $80^{\circ} \mathrm{C}$ for 2 days. $N, N^{\prime}$-dimethylethylene diamine $(10 \mathrm{~mol} \%)$ and $\mathrm{CuI}(10 \mathrm{~mol} \%)$ were added and the resulting suspension was heated at reflux for $6 \mathrm{~h}$ then left to stir at $80^{\circ} \mathrm{C}$ overnight. The mixture was then cooled down to rt, filtered through a pad of Celite, washed with EtOAc and DCM, and concentrated in vacuo. The residue was purified by flash chromatography eluting with $\mathrm{DCM} / \mathrm{MeOH}$ (100:0 to 90:10). Fractions containing the pure product were combined and concentrated to give $9 \mathbf{b}(6.4 \mathrm{~g}, 74 \%)$ as an off-white solid.

UPLC-MS (m/z): $251.3[\mathbf{M}+\mathbf{H}]^{+} .{ }^{1} \mathrm{H}$ NMR $\left(500 \mathrm{MHz}, \mathrm{CDCl}_{3}\right) \delta 7.41(\mathrm{dd}, J=2.8,0.8 \mathrm{~Hz}$, 1H), $7.39-7.28(\mathrm{~m}, 5 \mathrm{H}), 7.28-7.23(\mathrm{~m}, 1 \mathrm{H}), 6.79(\mathrm{~d}, J=8.8 \mathrm{~Hz}, 1 \mathrm{H}), 3.81(\mathrm{~s}, 3 \mathrm{H}), 3.79-$ $3.72(\mathrm{~m}, 1 \mathrm{H}), 3.71-3.64(\mathrm{~m}, 3 \mathrm{H}), 3.01(\mathrm{bs}, 1 \mathrm{H}), 2.79(\mathrm{bs}, 1 \mathrm{H}), 2.72-2.52(\mathrm{~m}, 2 \mathrm{H}), 2.37$ (ddt, $J=12.9,8.3,4.2 \mathrm{~Hz}, 1 \mathrm{H}), 2.27$ (ddd, $J=12.5,7.1,5.3 \mathrm{~Hz}, 1 \mathrm{H}), 2.22$ (s, 3H), 2.12 (dt, $J$ $=13.1,7.3 \mathrm{~Hz}, 1 \mathrm{H}), 1.85(\mathrm{bs}, 1 \mathrm{H})$. 
rac-2-(4-methoxy-3-methylphenyl)-2,7-diazaspiro[4.4]nonan-1-one (10b)

1-chloroethyl carbonochloridate $(2.55 \mathrm{~mL}, 1.3$ eq.) was added to a solution of $9 \mathbf{b}(6.4 \mathrm{~g}, 18$ $\mathrm{mmol})$ in DCE $(60 \mathrm{~mL}, 0.3 \mathrm{M})$. The reaction mixture was stirred at $80^{\circ} \mathrm{C}$ for $2 \mathrm{~h} 30$. Additional 1-chloroethyl carbonochloridate $(0.1 \mathrm{~mL})$ was added to the reaction mixture and stirred for further $1 \mathrm{~h}$. The reaction mixture was then concentrated. The residue was diluted in $\mathrm{MeOH}(60$ $\mathrm{mL}$ ) and stirred at $60^{\circ} \mathrm{C}$ for $2 \mathrm{~h}$ (gas evolution). The reaction mixture was concentrated, diluted in water and the solution was extracted with DCM. The aqueous layer was basified and extracted several times with DCM. Combined organic layers were washed with brine, dried over $\mathrm{Na}_{2} \mathrm{SO}_{4}$, filtered and concentrated to afford $\mathbf{1 0 b}(4.3 \mathrm{~g}, 91 \%)$ as an off-white solid. The product was used in the next step without further purification

UPLC-MS (m/z): $261.3[\mathbf{M}+\mathbf{H}]^{+} .{ }^{1} \mathrm{H}$ NMR $\left(500 \mathrm{MHz}, \mathrm{CDCl}_{3}\right) \delta 7.42-7.37(\mathrm{~m}, 1 \mathrm{H}), 7.36-$ $7.32(\mathrm{~m}, 1 \mathrm{H}), 6.81(\mathrm{~d}, J=8.8 \mathrm{~Hz}, 1 \mathrm{H}), 3.82(\mathrm{~s}, 3 \mathrm{H}), 3.80-3.74(\mathrm{~m}, 2 \mathrm{H}), 3.42(\mathrm{~d}, J=11.6 \mathrm{~Hz}$, $1 \mathrm{H}), 3.40-3.33(\mathrm{~m}, 1 \mathrm{H}), 3.26-3.18(\mathrm{~m}, 1 \mathrm{H}), 3.06(\mathrm{~d}, J=11.5 \mathrm{~Hz}, 1 \mathrm{H}), 2.38-2.23(\mathrm{~m}, 2 \mathrm{H})$, $2.22(\mathrm{~s}, 3 \mathrm{H}), 2.22-2.09(\mathrm{~m}, 1 \mathrm{H}), 1.96-1.84(\mathrm{~m}, 1 \mathrm{H})$.

Typical procedure for reductive amination

A suspension of (3-fluorophenyl)-2,7-diazaspiro[4.4]nonan-1-one I 9a (for E226) or 2-(4methoxy-3-methylphenyl)-2,7-diazaspiro[4.4]nonan-1-one 9b (for E228) (0.21 mmol) and the aldehyde $(0.23 \mathrm{mmol}, 1.1 \mathrm{eq})$ in THF $(1 \mathrm{~mL})$ was stirred at room temperature for 30 minutes. Sodium triacetoxyborohydride $(0.47 \mathrm{mmol}, 2.2 \mathrm{eq})$ was then added and the resulting mixture was stirred at room temperature overnight. The medium was treated with an aqueous solution of sodium bicarbonate, the aqueous layer was extracted with EA, the organic layer dried over sodium sulphate, filtered and the filtrate was concentrated under reduced pressure. Purification of the residue by preparative RP-HPLC (Puriflash) afforded desired compound. 
UPLC-MS (m/z): 359.2-361.2 $[\mathbf{M}+\mathbf{H}]^{+} .{ }^{1} \mathrm{H}$ NMR $(500 \mathrm{MHz}$, Chloroform- $d$ ) $\delta 7.56(\mathrm{dt}, J=$ 11.5, $2.3 \mathrm{~Hz}, 1 \mathrm{H}), 7.39-7.33(\mathrm{~m}, 2 \mathrm{H}), 7.30(\mathrm{td}, J=8.2,6.5 \mathrm{~Hz}, 1 \mathrm{H}), 7.26-7.18(\mathrm{~m}, 3 \mathrm{H}), 6.83$ $(\mathrm{tdd}, J=8.2,2.5,1.0 \mathrm{~Hz}, 1 \mathrm{H}), 3.79-3.65(\mathrm{~m}, 3 \mathrm{H}), 3.60(\mathrm{~d}, J=13.2 \mathrm{~Hz}, 1 \mathrm{H}), 2.97(\mathrm{td}, J=8.3$, $3.9 \mathrm{~Hz}, 1 \mathrm{H}), 2.77(\mathrm{~d}, J=9.2 \mathrm{~Hz}, 1 \mathrm{H}), 2.64(\mathrm{~d}, J=9.1 \mathrm{~Hz}, 1 \mathrm{H}), 2.56(\mathrm{q}, J=8.3 \mathrm{~Hz}, 1 \mathrm{H}), 2.38$ (ddd, $J=12.3,8.3,3.9 \mathrm{~Hz}, 1 \mathrm{H}), 2.29(\mathrm{ddd}, J=12.5,7.3,5.1 \mathrm{~Hz}, 1 \mathrm{H}), 2.15(\mathrm{dt}, J=12.6,7.2$ $\mathrm{Hz}, 1 \mathrm{H}), 1.83(\mathrm{dt}, J=12.7,7.8 \mathrm{~Hz}, 1 \mathrm{H})$.

\section{7-(3-chlorobenzyl)-2-(4-methoxy-3-methylphenyl)-2,7-diazaspiro[4.4]nonan-1-one} (E228)

UPLC-MS (m/z): 385.3-387.3 [M+H] ${ }^{+} .{ }^{1} \mathrm{H}$ NMR $(500 \mathrm{MHz}$, Chloroform- $d) \delta 7.42(\mathrm{dd}, J=$ 2.8, $0.9 \mathrm{~Hz}, 1 \mathrm{H}), 7.39-7.32(\mathrm{~m}, 2 \mathrm{H}), 7.24-7.22(\mathrm{~m}, 3 \mathrm{H}), 6.80(\mathrm{~d}, J=8.8 \mathrm{~Hz}, 1 \mathrm{H}), 3.81(\mathrm{~s}, 3 \mathrm{H})$, 3.75-3.64 (m, 3H), $3.60(\mathrm{~d}, J=13.2, \mathrm{~Hz}, 1 \mathrm{H}), 2.97(\mathrm{td}, J=8.3,3.7 \mathrm{~Hz}, 1 \mathrm{H}), 2.77(\mathrm{~d}, J=9.1$ $\mathrm{Hz}, 1 \mathrm{H}), 2.64(\mathrm{~d}, J=9.1 \mathrm{~Hz}, 1 \mathrm{H}), 2.55$ (q, $J=8.4 \mathrm{~Hz}, 1 \mathrm{H}), 2.37$ (ddd, $J=12.3,8.3,3.7 \mathrm{~Hz}$, 1H), $2.27(\mathrm{ddd}, J=12.5,7.1,5.3 \mathrm{~Hz}, 1 \mathrm{H}), 2.22(\mathrm{~s}, 3 \mathrm{H}), 2.13(\mathrm{dt}, J=12.5,7.3 \mathrm{~Hz}, 1 \mathrm{H}), 1.82$ $(\mathrm{dt}, J=12.6,7.8 \mathrm{~Hz}, 1 \mathrm{H})$.

Generation of primary mouse osteoclasts from bone marrow macrophages. Osteoclasts were differentiated from the bone marrow of 4 to 8 week-old $\mathrm{C} 57 \mathrm{BL} / 6 \mathrm{~J}$ mice as described ${ }^{29}$. Bone marrow cells were collected from femurs and tibia cultured in a humidified incubator at $37{ }^{\circ} \mathrm{C}$ and $5 \% \mathrm{CO}_{2}$ in growth medium: $\alpha$ MEM (Eagle's alpha Minimum Essential Medium), supplemented with $10 \%$ fetal calf serum and $2 \mathrm{mM}$ glutamine, for 24 hours, $3.10^{7}$ cells per $150 \mathrm{~mm}$ plates. Non adherent cells were collected and plated $5.10^{6}$ cells per $100 \mathrm{~mm}$ plate in growth medium supplemented with $100 \mathrm{ng} / \mathrm{mL}$ de MCS-F (macrophage colony stimulating factor) (Peprotech) for 48 hours. Cells were then scrapped plated in growth medium supplemented with $30 \mathrm{ng} / \mathrm{mL}$ de M-CSF and $100 \mathrm{ng} / \mathrm{mL}$ RANKL (Peprotech) in 24-well 
plates, $5 \times 10^{5}$ cells per well containing (immunofluorescence) or not (resorption assays) a glass coverslip. Medium was changed every other day for 4 to 5 days until osteoclast differentiate.

Podosome belt observation and resorption assays in mouse osteoclasts. For podosome belt observation, $2.5 \mu \mathrm{L}$ of compound solubilized at $20 \mathrm{mM}$ in $100 \%$ DMSO was added in the culture medium of differentiated osteoclasts, leading to a final concentration of $100 \mu \mathrm{M}$ in 0.5\% DMSO. Osteoclasts were incubated for 4 hours and then fixed with $3.6 \%$ Formalin (Sigma) for 10 minutes or the medium was changed for fresh medium without compound and cells were fixed after overnight recovery. Cells were then permeabilized with $0.1 \%$ Triton X100 in PBS for 1 min. After blocking with 1\% BSA in PBS for 30 min, osteoclasts were incubated for $1 \mathrm{~h}$ with anti-vinculin V9131 antibody (Sigma, 1:400) followed by $1 \mathrm{~h}$ with donkey Alexa488-anti-mouse antibody A21202 (Life Technologies, 1:1000) and Alexa647Phalloidin A22287 (Life Technologies) to visualize actin. Images were acquired manually with a Leica DM6000 wide field microscope using a 63X HCX Plan 0.6-1.32 NA oil objective.

For resorption assays, osteoclasts at days 3 of differentiation in 24-well plates were detached by incubation in Accutase (Sigma) for $5-10 \mathrm{~min}$ at $37^{\circ} \mathrm{C}$ and seeded onto inorganic crystalline calcium phosphate-coated multi-wells (Osteo Assay Surface, Corning). The following day, compounds were added to the culture medium at the relevant concentration in $0.5 \%$ DMSO, 8 wells per condition, and left for 48 hours. Four wells were then stained for TRAP to count osteoclasts and four wells with Von Kossa stain to measure calcium phosphate dissolution. TRAP staining was performed as reported previously ${ }^{30}$. Briefly, after fixation in $10 \%$ formalin for 10 minutes and wash with ethanol-acetone (1:1 vol:vol), osteoclasts were incubated with $0.1 \mathrm{mg} / \mathrm{ml}$ naphthol AS-MX phosphate and $0.6 \mathrm{mg} / \mathrm{ml}$ fast 
red violet LB salt in $0.1 \mathrm{M}$ sodium acetate buffer $\mathrm{pH} 5$ containing $50 \mathrm{mM}$ sodium tartrate for 1.5 hour at $37^{\circ} \mathrm{C}$. Staining of mineral matrix with von Kossa was done as described

previously ${ }^{31}$. Briefly, wells were incubated in $10 \%$ sodium hyperchlorite for $5 \mathrm{~min}$ to dislodge osteoclasts, rinsed with water, incubated with $\mathrm{AgNO}_{3} 5 \%$ for 10 min, rinsed with water, and incubated in a solution of $5 \%$ sodium carbonate in $10 \%$ formalin for $4 \mathrm{~min}$. After solution removal, wells were let to dry. Wells were imaged with a Nikon SMZ1000 stereomicroscope equipped with a Nikon DXM 1200F CCD camera; osteoclast we counted and reosorbed area measured using ImageJ $1.51 \mathrm{w}$ software. Data were analyzed using GraphPrism5 software.

\section{Generation of primary human osteoclasts from peripheral blood monocytes and} resorption assays. Primary human osteoclasts were generated and resorption assays performed by the ISO 9001-certified preclinical CRO Atlantic Bone Screen (atlantic-bonescreen.com, Nantes, France). Monocytic cells CD14 ${ }^{+}$cells were selected by magnetic sorting (MACS ${ }$, MiltenyiBiotec) from human peripheral blood according to manufacturor's instructions. Monocytes were differentiated into osteoclasts in differentiation medium: aMEM medium supplemented with 10\% FCS, M-CSF $(25 \mathrm{ng} / \mathrm{mL})$ and RANKL $(100 \mathrm{ng} / \mathrm{mL})$, $1.10^{6}$ cells per well in 6-well plates. After 4 days, cells were detached with Accutase and seeded in CaP-coated multi-wells (Osteo Assay Surface, Corning) for resorption measurement or on plastic 96-well plates for osteoclast counting, in differentiation medium. After 4 hours, compounds were added to the differentiation medium at the desired concentration at $0.1 \%$ DMSO final content. After 48 hours, cells were fixed and stained for TRAP and von Kossa as described above, osteoclasts were counted and resorption areas measured with Nikon NIS-D software. Data were analyzed using GraphPrism5 software. 
Rac-GTP pull-down experiments. HEK297T cells were transiently transfected with a pEGFP mammalian expression vector to express mouse or human (residues 1212-1642) DOCK5 DHR2 exchange domain with a GFP tag at the N-terminus with jetPEI according to manufacturer's instructions (Polyplus) and the levels of endogenous Rac-GTP were determined by pull down experiments as described ${ }^{20}$. Briefly, 24 hours after transfection, cells were trypsinized and split in 6 well plates, $1.10^{6}$ cells per well. After 24 hours, cells were incubated for 1 hour in the presence of $1 \%$ DMSO containing or not the inhibitory compounds then lysed in $50 \mathrm{mM}$ Tris $/ \mathrm{HCl}(\mathrm{pH} 7.4), 2 \mathrm{mM} \mathrm{MgCl} 2,1 \%$ Triton $\mathrm{X}-100,10 \%$ glycerol, $100 \mathrm{mM} \mathrm{NaCl}$ and protease inhibitor cocktail (Sigma) (FISH buffer). Cleared lysates were incubated with GST-PakCRIB (GST fused to the Cdc42/Rac binding domain of the kinase PAK1) bound to glutathione-coupled Sepharose beads (Cytoskeleton), $20 \mu \mathrm{g}$ per well lysate, for $45 \mathrm{~min}$ at $4{ }^{\circ} \mathrm{C}$ on a rotatory wheel. Beads were washed three times FISH buffer, eluted in Laemmli buffer and analyzed for PakCRIB-bound active GTP-Rac by western bolt. Active Rac band intensity was measured using ImageJ $1.51 \mathrm{w}$ software and normalized to cleared lysate cell protein concentration. Data were analyzed using GraphPrism5 software.

Nucleotide exchange assays. Human full-length RAC1 carrying a C-terminal 6-histidine tag and human TRIOGEF1 (residues R1232-T1550) were expressed in Escherichia coli and purified as described ${ }^{24}$. The exchange domain of human DOCK5 (residues 1212-1642, DOCK5) was expressed in Escherichia coli as a 6 His-MBP fusion with a TEV protease cleavage site and purified as described ${ }^{19}$. All proteins were purified to homogeneity (Figure S2A). RAC1 was loaded with mant-GDP (JenaBiosciences, Jena Germany) before nucleotide exchange kinetics experiments. Nucleotide exchange kinetics was measured by recording the decay in fluorescence following the dissociation of mant-GDP $(\lambda \mathrm{ex}=360 \mathrm{~nm}, \lambda \mathrm{Em}=440$ 
$\mathrm{nm}$ ) using a FlexStation fluorometer at $25^{\circ} \mathrm{C}$. The concentration of RAC1 was $2.0 \mu \mathrm{M}$ and the concentration of DOCK5 and TRIOGEF1 was $100 \mathrm{nM}$. All kinetics assays were carried out in a buffer containing $50 \mathrm{mM}$ Tris at $\mathrm{pH} 8,300 \mathrm{mM} \mathrm{NaCl}, 2 \mathrm{mM} \mathrm{MgCl}_{2}, 1 \mathrm{mM}$ DTT, $1 \%$ DMSO and were started by addition of $100 \mu \mathrm{M}$ GTP. Kobs values $\left(\mathrm{s}^{-1}\right)$ were determined by single exponential analysis as described ${ }^{21,24}$. All experiments were done in duplicate. Data were analyzed using KaleidaGraph.

Surgical procedure for ovariectomy. Mouse manipulation, bone histomorphometry and $\mu \mathrm{CT}$ were performed by Pharmatest Services Ltd. (Pharmatest) CRO (pharmatest.com, Turku, Finland) under animal experiment license $8263 / 04.10 .07 / 2015$ granted by National Animal Experiment Board, Regional State Administrative Agency for Southern Finland, Hämeenlinna, Finland. 12-week-old C57BL6/J mice were obtained from SCANBUR Research A/S, Karlslunde, Denmark, weighed and randomized into study groups by stratification according to their body weight, 10 mice per group. One day before surgery, blood samples were harvested from saphenous vein of all animals, after six hours fasting period. Ovariectomy (OVX) or control SHAM operations were performed at day 0 of the experiment, under anaesthesia and analgesia using a dorsal approach ${ }^{32}$. In the OVX operation, ovaries were removed together with oviducts. In the SHAM operation, abdomen was opened and ovaries identified without removing any tissue. Anaesthesia was performed using isoflurane inhalation (induction 4-5\%, maintenance 1-3\%) or i.p. injections of xylazine (6-11 mg/kg, i.p.) and ketamine (114-200 mg/kg, i.p.). Postoperative analgesia was performed using buprenorphine (10-50 $\mu \mathrm{g} / \mathrm{kg}$, s.c.) and carprofen (5 mg/kg, s.c.). Mice were terminated by asphyxiation using $\mathrm{CO}_{2}$ and by subsequent cervical dislocation. The successful of OVX operation was evaluated at necropsy and using the relative uterine weight at day 28. 
Blood volumes of $0.2 \mathrm{~mL}$ were harvested for serum samples from saphenous vein at the beginning of days $-1,13$ and 27 after six hours fasting period, into serum gel tubes including aluminium silica as a clotting activator (Microvette 200 Z-Gel, Sarstedt, Nümbrecht, Germany) and blood was allowed to clot for 30-60 minutes. Samples were then centrifuged at $10,000 \mathrm{x} \mathrm{g}$ for 5 minutes and the resultant serum was transferred to a clean sample tube, frozen at $-20^{\circ} \mathrm{C}$, and stored at $-70^{\circ}$. The levels of serum CTX-I bone resorption biomarker at days -1 and 13 were measured using enzyme-linked immunosorbent assay RatLaps ${ }^{\mathrm{TM}}$ (IDS Ltd, Boldon, UK), according to manufacturer's instructions. The levels of serum osteocalcin bone turnover biomarker at days -1 and 27 were measured using Mouse Osteocalcin Enzyme Immunoassay Kit (Alfa Aesar / Thermo Fisher Scientific, Tewksbury, MA, USA), according to manufacturer's instructions.

Prevention of OVX-induced osteoporosis. From day 1 after the operation, SHAM-operated control mice and OVX control mice were treated with vehicle $(0.485 \%$ carboxymethylcellulose and 3\% Tween 80), $10 \mathrm{~mL} / \mathrm{kg}$, intraperitoneal (i.p.) every day. Alternatively, OVX mice were treated with E197 (20 mg/kg in vehicle, $10 \mathrm{~mL} / \mathrm{kg}$, i.p.) q.d. or b.i.d., with at least 6 hours between dosing, or OVX mice received subcutaneous injections of zoledronate, a bisphosphonate used in the clinics, $100 \mu \mathrm{g} / \mathrm{kg}$ in $0.9 \%$ weight/volume sodium chloride $\mathrm{NaCl}$, every other week. For measuring dynamic parameters, bone was labeled twice with fluorescent dyes: oxytetracycline at day 21 and calcein green at day 26 . Terramycin Vet solution (Zoetis Finland, Helsinki, Finland) was diluted in $0.9 \% \mathrm{NaCl}$ in order to obtain a dosing solution containing $3 \mathrm{mg} / \mathrm{mL}$ of oxytetracycline; solid calcein green (Sigma) was dissolved in $0.9 \% \mathrm{NaCl}$ at $\mathrm{pH} 7.2$ in order to obtain a $2 \mathrm{mg} / \mathrm{mL}$ calcein green solution. These labeling solutions were administered subcutaneously at the volume of $5 \mathrm{~mL} / \mathrm{kg}$, resulting in a dose of $15 \mathrm{mg} / \mathrm{kg}$ for oxytetracycline and a dose of $10 \mathrm{mg} / \mathrm{kg}$ for calcein green. At day 28, 
right and left femurs and tibias were harvested from each mouse. Skin covering the right and left limbs were removed and the limbs dissected. Then, the femora and tibia were detached and dissected free of surrounding tissues without injuring the bones including their articular surfaces and periosteum. Femur samples were stored in $40 \%$ ethanol (Altia, Rajamäki, Finland) immediately after the dissection. The next day, the samples were stored in $70 \%$ ethanol for histomorphometry. Tibia samples were fixed in $10 \%$ formalin and stored in $70 \%$ ethanol for $\mu \mathrm{CT}$.

Histomorphometrical and $\boldsymbol{\mu C T}$ analysis of bones. The amount, microarchitecture, cellular characteristics and metabolic activity of metaphyseal trabecular bone and the amount and metabolic activity of diaphyseal cortical bone were analyzed in femurs harvested at day 28 by bone histomorphometry ex vivo, as described ${ }^{33-35}$. Briefly, fixed samples were dehydrated in a series of incubations at increasing ethanol concentrations, defatted in xylene (FF-Chemicals, Haukipudas, Finland), and embedded in methyl methacrylate (Merck kGaA, Darmstadt, Germany). After the embedding, longitudinal sections were obtained from a standardized site of bone marrow cavity in right distal metaphysis using a fully motorized rotary microtome and a tungsten-carbide knife. Static trabecular bone parameters were determined in one $4-\mu \mathrm{m}-$ thick section stained in Masson-Goldner's Trichrome and dynamic trabecular bone parameters in one 8 - $\mu \mathrm{m}$-thick unstained section using a region of interest with the total area of $0.75 \mathrm{~mm}^{2}$. In addition, cross-sectional cylinders were prepared from a standardized site of diaphysis in left femur in a transverse plane using a linear precision saw and a diamond blade. Both static and dynamic cortical bone parameters were determined in one unstained $200-\mu \mathrm{m}$-thick cylinder using the entire cross-sectional area of bone as region of interest. All parameters were analyzed by OsteoMeasure7 histomorphometry system (OsteoMetrics, Atlanta, GA, USA) and following the guidelines of the American Society for Bone and Mineral Research ${ }^{33}$. 
Bone parameters were measured in right tibia stored in $70 \%$ ethanol by $\mu \mathrm{CT}$ as described ${ }^{36,37}$, using Bruker SkyScan 1276 High-Resolution Micro-CT Scanner (Bruker microCT, Kontich, Belgium). In each measurement, the sample was aligned with the horizontal axis of the scanner and its measurement was performed using the following image acquisition, processing and reconstruction settings: for X-ray scanning, X-ray voltage: $55 \mathrm{kV}, \mathrm{X}$-ray current: $80 \mu \mathrm{A}$, filter: $0.5 \mathrm{~mm}$ aluminium (A), camera resolution: 4032 pixels, image pixel size: $4 \mu \mathrm{m}$, tomographic rotation: $180^{\circ}$, rotation step: $0.3^{\circ}$, frame averaging: 2 ; for reconstruction: image format: 8-bit bmp, smoothing: 0, ring artefact correction: 10, beam hardening correction: $30 \%$, histogram limits: $\min 0.0000$ - max 0.1350 . In the reconstructed data of each tibia, the uncalcified cartilage of epiphyseal growth plate was defined as a reference level and the volume of interest was segmented using a freehand drawing tool separately for metaphyseal trabecular bone and diaphyseal cortical bone. The analysis of metaphyseal trabecular bone was performed using volume of interest with the longitudinal length of $0.75 \mathrm{~mm}$ and starting $0.25 \mathrm{~mm}$ below the reference level. The analysis of diaphyseal cortical bone was performed using volume of interest with the longitudinal length of $0.25 \mathrm{~mm}$ and starting $6.75 \mathrm{~mm}$ below the reference level. The grey threshold value of 68 was used as a binarization limit for metaphyseal trabecular bone and the grey threshold value of 90 as a binarization limit for diaphyseal cortical bone.

OVX mice data analysis. The effects of OVX were studied by comparing OVX control mice treated with vehicle with Sham-operated control mice treated with vehicle. The effects of treatments were studied by comparing OVX mice treated with ZOL or E197. One of the 10 samples of right femur for histomorphometry in the control OVX group exhibited abnormally high amount of trabecular bone when compared with other mice in the same group: $2.6 \mathrm{x}$ standard deviation higher than the mean value of the group and $2.4 \mathrm{x}$ standard deviation higher 
than the second highest value of the group; subsequently, bone histomorphometry results obtained from the trabecular bone of this mouse were considered as outliers and removed from the study.

All statistical analyses were performed with as two-sided tests using either parametric or nonparametric tests using GraphPrism5 software; p-value lower than 0.05 was considered statistically significant. The use of data transformations and non-parametric tests were decided after examining assumptions of statistical models: the normality of data distribution by Shapiro-Wilk test and the homogeneity of variances by Levene's test. In a case of violating these assumptions, logarithmic transformation was applied. If the assumptions of statistical models were fulfilled as such or after data transformation, differences among groups were evaluated using parametric one-way analysis of variance (ANOVA). If the oneway ANOVA revealed statistically significant differences, linear contrasts of means were used for statistical comparisons between groups. If the assumptions of statistical models were not fulfilled even after data transformations, non-parametric Kruskal-Wallis test was used to evaluate differences among groups. If the Kruskal-Wallis test revealed statistically significant differences, non-parametric Mann-Whitney U test was used for statistical comparisons between groups. 


\section{Supporting information}

Supporting Information 1 shows LC spectra of E73 and derivatives; Supporting Information 2 Shows MS spectra of E73 derivatives; Supporting Information 3 shows 1H NMR spectra of E73 and derivatives; Supporting Information 4 shows analyses of the $1 \mathrm{~g}$ E197 synthesized for in vivo experiments in the mouse; Supporting Information 5 lists the molecular formula strings; Supporting Information 6 displays the Supplementary Figures 1, 2 and 3

\section{Corresponding Author}

A.B.: email, anne.blangy@crbm.cnrs.fr; phone, +33 434359508.

Present address of L.M.: lucile.mounier@cirad.fr

UMR Cirad-Inra ASTRE « Animal, Santé, Territoires, Risques et Ecosystèmes », Campus international de Baillarguet, 34398 Montpellier CEDEX 5, France

Present address of M. G.: marinefrezza@hotmail.com

481 chemin du haut Privas, 69390 Charly, France.

\section{Author contributions}

A.B. designed the study and wrote the manuscript, which was contributed by all authors, who have approved the submitted version of the manuscript. L.M. performed all cellular experiments in HEK293T cells and mouse osteoclasts. A.M. contributed to the analysis of the experiments with mouse osteoclasts. J.M. and J.V. supervised the in vivo experiments in the mouse and analyzed the data. Y.F. and J.C. performed the in vitro experiments. M.G. and D.R. designed, synthetized, purified and analyzed the compounds. 


\section{Acknowledgements}

This study was supported by the French Centre National de la Recherche Scientifique (CNRS), Montpellier University, by grant DEQ20160334933 from the Fondation pour la Recherche Médicale and grant AxLR-Dock5 from the Société d'Accélération du Transfert de Technologies (SATT) AxLR to A.B., and by a grant from the LabEx LERMIT to J.C. We specially thank Marc Criton form the SATT AxLR for fruitful discussions and advice. We acknowledge the imaging facility MRI (Montpellier, France), member of the national infrastructure France-BioImaging supported by the French National Research Agency (ANR10-INBS-04, "Investments for the future").

\section{Disclosures}

A.B. and L.M. are inventors of patent WO2019197659 related to the family of compounds described in this article. J.M. and J.V. are full-time employees of Pharmatest Services Ltd Pharmatest Services Ltd. M.G. was full-time employees of Edelris at the time this work was carried out and D.R. is full-time employees of Edelris. A.M., M.G., D.R., Y.F and J.C. state that they have no conflicts of interest.

\section{Abbreviations used}

alpha-MEM, Eagle's alpha Minimum Essential Medium; ANOVA, one-way analysis of variance; $\mathrm{BV} / \mathrm{TV}$, percent bone volume per total volume; cHx, cyclohexane; $\mathrm{CRO}$, contract research organization; Ct.Th, cortical thickness; CTX-I, C-terminal cross-linked telopeptides of type I collagen; DA, Degree of anisotropy; EA, ethyl acetate; GEF, guanine nucleotide exchange factor; mant-GDP, N-methylanthraniloyl-GDP; MCS-F, macrophage colony stimulating factor; OVX, ovariectomy; RANKL, receptor activator of nuclear factor- $\mathrm{\kappa B}$ ligand; SMI, structure model index; Tb.N, trabecular number; Tb.Sp, trabecular separation; 
Tb.Pf, trabecular pattern factor; Tb.Th, trabecular thickness; TRAP, tartrate resistant acid phosphatase; TRIOGEF1, TRIO exchange domain 1; ZOL, zoledronate; $\mu \mathrm{CT}$, microcomputed tomography. 


\section{References}

(1) Florencio-Silva, R.; Sasso, G. R. da S.; Sasso-Cerri, E.; Simões, M. J.; Cerri, P. S.

Biology of Bone Tissue: Structure, Function, and Factors That Influence Bone Cells. BioMed Res. Int. 2015, 2015, 1-17.

(2) Manolagas, S. C.; Jilka, R. L. Bone Marrow, Cytokines, and Bone Remodeling Emerging Insights into the Pathophysiology of Osteoporosis. N. Engl. J. Med. 1995, 332, $305-311$.

(3) Compston, J. E.; McClung, M. R.; Leslie, W. D. Osteoporosis. Lancet Lond. Engl. 2019, 393, 364-376.

(4) Coury, F.; Peyruchaud, O.; Machuca-Gayet, I. Osteoimmunology of Bone Loss in Inflammatory Rheumatic Diseases. Front. Immunol. 2019, 10, 679.

(5) Madel, M.-B.; Ibáñez, L.; Wakkach, A.; de Vries, T. J.; Teti, A.; Apparailly, F.; BlinWakkach, C. Immune Function and Diversity of Osteoclasts in Normal and Pathological Conditions. Front. Immunol. 2019, 10, 1408.

(6) Croucher, P. I.; McDonald, M. M.; Martin, T. J. Bone Metastasis: The Importance of the Neighbourhood. Nat. Rev. Cancer 2016, 16, 373-386.

(7) Buckley, L.; Humphrey, M. B. Glucocorticoid-Induced Osteoporosis. N. Engl. J. Med. 2018, 379, 2547-2556.

(8) Bettis, T.; Kim, B.-J.; Hamrick, M. W. Impact of Muscle Atrophy on Bone Metabolism and Bone Strength: Implications for Muscle-Bone Crosstalk with Aging and Disuse. Osteoporos. Int. USA 2018, 29, 1713-1720.

(9) Raynaud-Messina, B.; Verollet, C.; Maridonneau-Parini, I. The Osteoclast, a Target Cell for Microorganisms. Bone 2019, 127, 315-323.

(10) Cremers, S.; Drake, M. T.; Ebetino, F. H.; Bilezikian, J. P.; Russell, R. G. G. 
Pharmacology of Bisphosphonates. Br. J. Clin. Pharmacol. 2019, 85, 1052-1062.

(11) Deeks, E. D. Denosumab: A Review in Postmenopausal Osteoporosis. Drugs Aging 2018, 35, 163-173.

(12) Drissi, H.; Sanjay, A. The Multifaceted Osteoclast; Far and Beyond Bone Resorption. J. Cell. Biochem. 2016, 117, 1753-1756.

(13) Teitelbaum, S. L. Therapeutic Implications of Suppressing Osteoclast Formation versus Function. Rheumatol. Oxf. Engl. 2016, 55, ii61-ii63.

(14) Drake, M. T.; Clarke, B. L.; Oursler, M. J.; Khosla, S. Cathepsin K Inhibitors for Osteoporosis: Biology, Potential Clinical Utility, and Lessons Learned. Endocr. Rev. 2017, $38,325-350$.

(15) Pederson, L.; Ruan, M.; Westendorf, J. J.; Khosla, S.; Oursler, M. J. Regulation of Bone Formation by Osteoclasts Involves Wnt/BMP Signaling and the Chemokine Sphingosine-1-Phosphate. Proc Natl Acad Sci U A 2008, 105, 20764-20769.

(16) Stone, J. A.; McCrea, J. B.; Witter, R.; Zajic, S.; Stoch, S. A. Clinical and Translational Pharmacology of the Cathepsin K Inhibitor Odanacatib Studied for Osteoporosis. Br. J. Clin. Pharmacol. 2019, 85, 1072-1083.

(17) Blangy, A.; Bompard, G.; Guerit, D.; Marie, P.; Maurin, J.; Morel, A.; Vives, V. The Osteoclast Cytoskeleton - Current Understanding and Therapeutic Perspectives for Osteoporosis. J. Cell Sci. 2020, 133, jcs244798.

(18) Murphy, M. G.; Cerchio, K.; Stoch, S. A.; Gottesdiener, K.; Wu, M.; Recker, R. Effect of L-000845704, an AlphaVbeta3 Integrin Antagonist, on Markers of Bone Turnover and Bone Mineral Density in Postmenopausal Osteoporotic Women. J Clin Endocrinol Metab 2005, 90, 2022-2028.

(19) Ferrandez, Y.; Zhang, W.; Peurois, F.; Akendengué, L.; Blangy, A.; Zeghouf, M.; Cherfils, J. Allosteric Inhibition of the Guanine Nucleotide Exchange Factor DOCK5 by a 
Small Molecule. Sci. Rep. 2017, 7, 14409.

(20) Vives, V.; Laurin, M.; Cres, G.; Larrousse, P.; Morichaud, Z.; Noel, D.; Côté, J.-F.; Blangy, A. The Rac1 Exchange Factor Dock5 Is Essential for Bone Resorption by Osteoclasts. J. Bone Miner. Res. 2011, 26, 1099-1110.

(21) Vives, V.; Cres, G.; Richard, C.; Busson, M.; Ferrandez, Y.; Planson, A.-G.; Zeghouf, M.; Cherfils, J.; Malaval, L.; Blangy, A. Pharmacological Inhibition of Dock5 Prevents Osteolysis by Affecting Osteoclast Podosome Organization While Preserving Bone Formation. Nat. Commun. 2015, 6, 6218.

(22) Zhou, A.; Rayabarapu, D.; Hanson, P. R. "Click, Click, Cyclize”: A DOS Approach to Sultams Utilizing Vinyl Sulfonamide Linchpins. Org. Lett. 2009, 11, 531-534.

(23) Craven, P.; Aimon, A.; Dow, M.; Fleury-Bregeot, N.; Guilleux, R.; Morgentin, R.; Roche, D.; Kalliokoski, T.; Foster, R.; Marsden, S. P.; Nelson, A. Design, Synthesis and Decoration of Molecular Scaffolds for Exploitation in the Production of Alkaloid-like Libraries. Bioorg. Med. Chem. 2015, 23, 2629-2635.

(24) Peurois, F.; Veyron, S.; Ferrandez, Y.; Ladid, I.; Benabdi, S.; Zeghouf, M.; Peyroche, G.; Cherfils, J. Characterization of the Activation of Small GTPases by Their GEFs on Membranes Using Artificial Membrane Tethering. Biochem. J. 2017, 474, 1259-1272. (25) Pozzi, S.; Vallet, S.; Mukherjee, S.; Cirstea, D.; Vaghela, N.; Santo, L.; Rosen, E.; Ikeda, H.; Okawa, Y.; Kiziltepe, T.; Schoonmaker, J.; Xie, W.; Hideshima, T.; Weller, E.; Bouxsein, M. L.; Munshi, N. C.; Anderson, K. C.; Raje, N. High-Dose Zoledronic Acid Impacts Bone Remodeling with Effects on Osteoblastic Lineage and Bone Mechanical Properties. Clin. Cancer Res. 2009, 15, 5829-5839.

(26) Touaitahuata, H.; Cres, G.; de Rossi, S.; Vives, V.; Blangy, A. The Mineral Dissolution Function of Osteoclasts Is Dispensable for Hypertrophic Cartilage Degradation during Long Bone Development and Growth. Dev. Biol. 2014, 393, 57-70. 
(27) Mackie, E. J.; Ahmed, Y. A.; Tatarczuch, L.; Chen, K. S.; Mirams, M. Endochondral Ossification: How Cartilage Is Converted into Bone in the Developing Skeleton. Int $J$ Biochem Cell Biol 2008, 40, 46-62.

(28) Sato, D.; Takahata, M.; Ota, M.; Fukuda, C.; Tsuda, E.; Shimizu, T.; Okada, A.; Hiruma, Y.; Hamano, H.; Hiratsuka, S.; Fujita, R.; Amizuka, N.; Hasegawa, T.; Iwasaki, N. Siglec-15-Targeting Therapy Increases Bone Mass in Rats without Impairing Skeletal Growth. Bone 2018, 116, 172-180.

(29) Brazier, H.; Pawlak, G.; Vives, V.; Blangy, A. The Rho GTPase Wrch1 Regulates Osteoclast Precursor Adhesion and Migration. Int. J. Biochem. Cell Biol. 2009, 41, 13911401.

(30) Brazier, H.; Stephens, S.; Ory, S.; Fort, P.; Morrison, N.; Blangy, A. Expression Profile of RhoGTPases and RhoGEFs during RANKL-Stimulated Osteoclastogenesis: Identification of Essential Genes in Osteoclasts. J. Bone Miner. Res. 2006, 21, 1387-1398.

(31) Guérit, D.; Marie, P.; Morel, A.; Maurin, J.; Verollet, C.; Raynaud-Messina, B.; Urbach, S.; Blangy, A. Primary Myeloid Cell Proteomics and Transcriptomics: Importance of ß Tubulin Isotypes for Osteoclast Function. J. Cell Sci. 2020, 133, jcs239772.

(32) Idris, A. I. Ovariectomy/Orchidectomy in Rodents. In Bone Research Protocols; Helfrich, M. H., Ralston, S. H., Eds.; Methods in Molecular Biology; Humana Press: Totowa, NJ, 2012; Vol. 816, pp 545-551.

(33) Dempster, D. W.; Compston, J. E.; Drezner, M. K.; Glorieux, F. H.; Kanis, J. A.; Malluche, H.; Meunier, P. J.; Ott, S. M.; Recker, R. R.; Parfitt, A. M. Standardized Nomenclature, Symbols, and Units for Bone Histomorphometry: A 2012 Update of the Report of the ASBMR Histomorphometry Nomenclature Committee. J. Bone Miner. Res. 2013, 28, 2-17.

(34) Rissanen, J. P.; Halleen, J. M. Models and Screening Assays for Drug Discovery in 
Osteoporosis. Expert Opin. Drug Discov. 2010, 5, 1163-1174.

(35) Erben, R. G.; Glösmann, M. Histomorphometry in Rodents. In Bone Research Protocols; Helfrich, M. H., Ralston, S. H., Eds.; Methods in Molecular Biology; Humana Press: Totowa, NJ, 2012; Vol. 816, pp 279-303.

(36) Bouxsein, M. L.; Boyd, S. K.; Christiansen, B. A.; Guldberg, R. E.; Jepsen, K. J.; Müller, R. Guidelines for Assessment of Bone Microstructure in Rodents Using MicroComputed Tomography. J. Bone Miner. Res. 2010, 25, 1468-1486.

(37) van 't Hof, R. J. Analysis of Bone Architecture in Rodents Using Microcomputed Tomography. In Bone Research Protocols; Helfrich, M. H., Ralston, S. H., Eds.; Methods in Molecular Biology; Humana Press: Totowa, NJ, 2012; Vol. 816, pp 461-476. 
Table of Contents Graphic

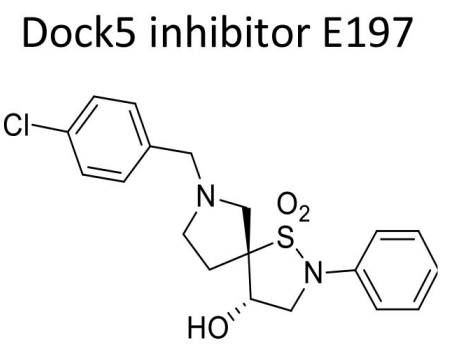

Human osteoclast activity

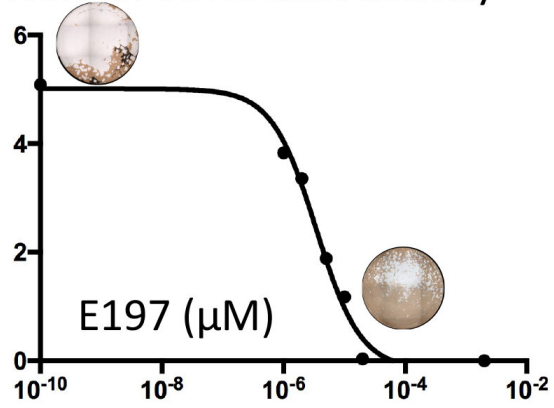

Mouse osteoporosis model

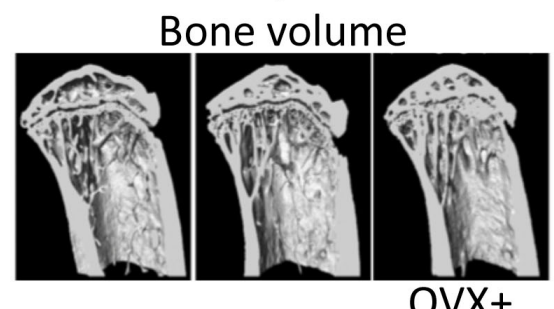

Control

ovx

E197

$21 \% \quad 17 \% \quad 25 \%$ 